\title{
Plastic additives and legacy persistent organic pollutants in the preen gland oil of seabirds sampled across the globe
}

Rei YAMASHITA ${ }^{1,2)}$, Nagako HIKI ${ }^{1)}$, Fumika KASHIWADA ${ }^{1)}$, Hideshige TAKADA ${ }^{12 *}$, Kaoruko MIZUKAWA ${ }^{12}$, Britta Denise HARDESTY ${ }^{3,4)}$, Lauren ROMAN ${ }^{3,5}$, David HYRENBACH ${ }^{(6)}$, Peter G. RYAN ${ }^{7}$, Ben J. DILLEY ${ }^{7}$, Juan Pablo MUÑOZ-PÉREZ ${ }^{8,9}$, Carlos A. VALLE ${ }^{8}$, Christopher K. PHAM $^{10)}$, João FRIAS ${ }^{11)}$, Bungo NISHIZAWA ${ }^{12)}$, Akinori TAKAHASHI ${ }^{12)}$, Jean-Baptiste THIEBOT ${ }^{12}$, Alexis WILL $^{13)}$, Nobuo KOKUBUN ${ }^{12}$, Yuuki Y. WATANABE ${ }^{12)}$, Takashi YAMAMOTO ${ }^{14,15)}$, Kozue SHIOMI ${ }^{12,16)}$, Ui SHIMABUKURO ${ }^{17)}$ and Yutaka WATANUKI ${ }^{18)}$

1) Laboratory of Organic Geochemistry, Tokyo University of Agriculture and Technology, Fuchu, Tokyo 183-8509, Japan

2) Atmosphere and Ocean Research Institute, The University of Tokyo, Kashiwa-shi, Chiba, 277-8564, Japan

3) CSIRO Oceans and Atmosphere, Hobart, Tas 7001, Australia

4) Centre for Marine Sociology, University of Tasmania, Hobart, Tasmania, Australia

${ }^{5)}$ Institute for Marine and Antarctic Studies, University of Tasmania, Hobart, TAS, Australia

6) Marine Science Programs at Oceanic Institute, Hawaii Pacific University, Waimanalo, HI 96795, USA

7) FitzPatrick Institute of African Ornithology, DST-NRF Centre of Excellence, University of Cape Town, Rondebosch 7701, South Africa

8) Colegio de Ciencias Biológicas y Ambientales COCIBA and Galápagos Science Center GSC, Universidad San Francisco de Quito USFQ, Quito, Ecuador

9) Faculty of Science and Engineering, University of the Sunshine Coast, QLD, Australia

10) OKEANOS R\&D Centre, University of the Azores, 9900-862, Horta, Portugal

11) Marine and Freshwater Research Centre (MFRC), Galway-Mayo Institute of Technology (GMIT), Dublin Rd., Galway H91 T8NW, Ireland

12) National Institute of Polar Research, Tachikawa, Tokyo 190-8518, Japan

${ }^{13)}$ Institute of Arctic Biology, University of Alaska Fairbanks, Fairbanks, Alaska, USA

14) Graduate School of Environmental Studies, Nagoya University, Nagoya, Aichi 464-8601, Japan

15) Meiji Institute for Advanced Study of Mathematical Sciences, Organization for the Strategic Coordination of Research and Intellectual Properties, Meiji University, Nakano, Tokyo 164-8525, Japan

16) Frontier Research Institute for Interdisciplinary Sciences, Tohoku University, Sendai, Miyagi 980-8578, Japan

17) Department of Polar Science, The Graduate University for Advanced Studies, SOKENDAI, Tachikawa, Tokyo 190-8518, Japan

${ }^{18)}$ Faculty of Fisheries Sciences, Hokkaido University, Hakodate, Hokkaido 041-8611, Japan

[Received May 13, 2021; Accepted August 1, 2021]

\section{ABSTRACT}

Plastic pollution, and its associated impacts on marine fauna due to chemical contamination, is an area of growing global concern. We analyzed 145 preen gland oil samples from 32 seabird species belonging to 8 families with different foraging habits and life history strategies from around the world for plastic additives and legacy persistent organic pollutants. The additives included two brominated flame retardants (decabromodiphenyl ether, BDE209; decabromo diphenyl ethane, DBDPE) and six benzotriazole UV stabilizers (BUVSs; UVP, UV326, UV329, UV328, UV327, and UV234). Polychlorinated biphenyls (PCBs) and organochlorine pesticides (Dichlorodiphenyltrichloroethane and its metabolites: DDTs and hexachlorocyclohexane: $\mathrm{HCHs}$ ) were detected ubiquitously. High concentrations of PCBs (up to 20,000 ng / g-lipid) were observed in the seabirds from higher-trophic level taxa. These patterns can be attributed to PCB exposure via their diet and associated biomagnification. DDT concentrations showed strong

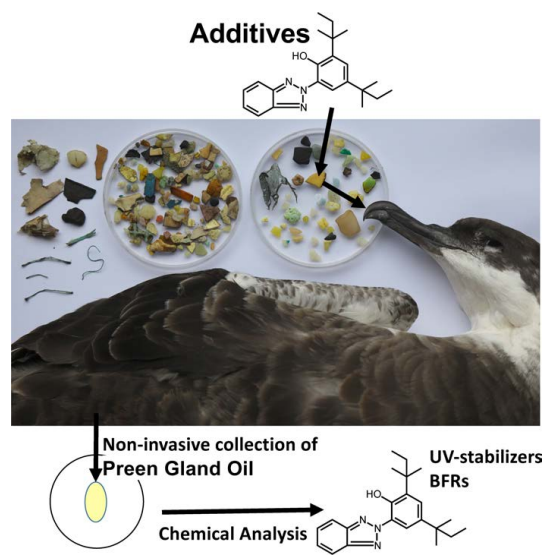

* Corresponding Author: shige@cc.tuat.ac.jp

This article is licensed under a Creative Commons [Attribution

4.0 International] license.

(C) 2021 The Authors. 
positive correlations with PCB concentrations, suggesting that DDTs in seabirds are also a result of diet and biomagnification. Plastic additives were detected sporadically as BDE209 and DBDPE were detected in 16 seabirds from 10 species (range: 3-379 ng/g-lipid) and BUVSs were detected in 46\% (67) of the examined individuals (range: 2-7,055 ng/g-lipid). UV stabilizers were more frequently detected than flame retardants because UV stabilizers are more widely applied to plastic products. None of the plastic additives were correlated to the presence of PCBs, nor were they explained by the foraging area or trophic level. High concentrations of additives were detected in the species with high levels of plastic in their digestive tracts. In some of these species, such as Hawaiian petrels (Pterodroma sandwichensis) from Hawaii and flesh-footed shearwaters (Ardenna carneipes) from Western Australia, plastics were directly observed in the stomach. For other species, including great shearwaters (Ardenna gravis) from Gough Island, blue petrels (Halobaena caerulea) from Marion Island, and black-footed and Laysan albatrosses (Phoebastria nigripes and P. immutabilis) from Hawaii, plastic ingestion has been documented in literature. These patterns can be explained if the additives are mainly from ingested plastics rather than diet. The detection of BFRs and BUVSs demonstrated that a significant proportion of the examined seabirds accumulated chemicals from ingested plastics.

Key words: preen gland oil; seabirds; plastic ingestion; plastic additives; persistent organic pollutants (POPs); brominated flame retardants; benzotriazole UV stabilizers; marine plastic pollution; plastic debris

\section{INTRODUCTION}

Globally, approximately 400 million metric tons of plastics are produced each year (Geyer et al., 2017), and a portion of these escape into the environment, eventually finding their way into the oceans. The volume of plastics entering the marine environment is estimated to be several million tons per year (Jambeck et al., 2015). When floating on the sea surface or stranded on beaches, plastics are exposed to UV radiation and then break down into smaller fragments. Plastic resin pellets are a feedstock of plastic products and arrive in marine environments through spillage during their handling and transport, followed by surface runoff. As they are not biodegradable and are either positively or neutrally buoyant, plastic fragments and resin pellets are distributed throughout the ocean. Consequently, huge amounts of plastics (i.e., 250,000 tons of plastics; Eriksen et al., 2014) are available to a suite of consumers in the world's oceans.

Plastics in the oceans are ingested by various marine organisms depending on their size (Jâms et al., 2020). Because of the size $(\mathrm{mm}$ to $\mathrm{cm}$ ) overlap between small ocean-floating plastic fragments and seabird prey (Roman et al., 2019c), seabirds are susceptible to plastic exposure and ingestion. Many papers have reported the detection of plastics in the digestive tracts of seabirds (Ryan, 2016; Roman et al., 2019a, and references therein). As of 2020, 180 species of seabirds, corresponding to half of the total species of seabirds around the globe, have been reported to have ingested plastics (Kühn and van Franeker, 2020). While the plastic ingestion rate (frequency of the occurrence of plastics in digestive tracts) of marine organisms has been increasing for many species (Ryan, 2016; Tanaka et al., 2018; Kühn and van Franeker, 2020), some species do not show significant trends (Baak et al., 2020a,b; van Franeker et al., 2021; Vlietstra and Parga, 2002). It has been predicted that by $2050,99 \%$ of seabird species will have ingested plastics (Wilcox et al., 2015). The physical damage and direct mortality caused by ingested plastics has been widely reported (Pierce et al., 2004; Wright et al., 2013; Roman et al., 2019b; Roman et al., 2020a; Roman et al., 2021a). In addition, the potential toxicological impact caused by hazardous chemicals associated with ingested plastics is concerning (Teuten et al., 2009) because marine plastic debris contains many hazardous chemicals (Hirai et al., 2011). While we have a reasonable understanding of the risk of entanglement and ingestion to major marine taxa (Wilcox et al., 2016), the risks associated with chemicals in marine plastics are insidious and inherently more difficult to document through the observation of manifested disorders. Assessing ecosystem functions requires the detection of potential increases in the burden of multiple chemicals from a range of sources in the body and the associated biochemical or genetic-level changes. The chemicals in marine plastic debris can be categorized into two broad categories: 1) hydrophobic chemicals that have been absorbed from the surrounding seawater and 2) additives that were originally compounded into the plastic products (Teuten et al., 2009). To aid in our assessment of the chemical risks associated with marine plastic ingestion in seabirds, our study focused on additives, which are the inherent components of plastic products.

Chemical additives (including plasticizers, UV stabilizers, antioxidants, and flame retardants) are compounded into plastic products to maintain or improve their quality (Andrady and Rajapakse, 2017). These additives represent $7 \%$ of the total plastic production and are essential components of plastic products. Among them, our study focused on brominated flame retardants (BFR), i.e., decabromo diphenyl ether (BDE209) and decabromo diphenyl ethane (DBDPE). BDE209 and DBDPE are persistent in the environment, bioaccumulate in organism tissues, and have been shown to have adverse effects on marine organisms and humans (McDonald, 2002; Nakari and Huhtala, 2010). Owing to its associated health risks, the production and use of BDE209 has been regulated by the Stockholm Convention since 2017. Another class of target additives in our study is benzotriazole-type UV stabilizers (BUVSs), including UVP, UV326, UV329, UV328, UV327, and UV234. These BUVSs are compounded into a wide range of plastic products to slow weathering from UV radiation. BUVSs, i.e., UV320, UV326, UV327, and UV328, are widely added to multiple-use plastic items (often called "user items"), including food packaging and fishing gear (Rani et al., 2017). However, the endocrine-disrupting potential of these chemicals has previously been demonstrated (Nagayoshi et al., 2015; Feng et al., 2020; Sakuragi et al., 2021). Because of their adverse effects 
and persistence, some BUVSs are now regulated by governmental and international regulations (e.g., ECHA, 2020). Recently, UV328 has been examined as a candidate of persistent organic pollutants (POPs), which are regulated by the Stockholm Convention (Persistent Organic Pollutants Review Committee, 2021).

Target BFRs and BUVSs are moderately to highly hydrophobic and have a high affinity with hydrophobic polymer matrices (Teuten et al., 2009; Yamashita et al., 2019). Many of them are not easily leached during usage and even after disposal because of their hydrophobic nature. Thus, hydrophobic additives are retained in plastic fragments in marine environments; BDE209 has been detected in microplastics collected from coastal waters and in the open ocean (Yeo et al., 2020) and BUVSs have been detected in beached plastic fragments (Rani et al., 2017; Tanaka et al., 2020a). Furthermore, BFRs and BUVSs have been found in plastic fragments collected from the stomachs of northern fulmars (Fulmarus glacialis) and in regurgitated boluses from albatrosses (Tanaka et al., 2019). It was believed that additives are not easily available for leaching or accumulation in biological tissues as they are kneaded into the polymer matrix (Sun et al., 2019). However, it has been demonstrated that oily components in digestive fluids can act as organic solvents to facilitate the leaching of hydrophobic additives (Tanaka et al., 2015; Kühn et al., 2020). The transfer and accumulation of additives from ingested plastics to the tissues in seabirds has been demonstrated in semifield feeding experiments with plastics compounded with additives (Tanaka et al., 2020b). There remain questions, however, about the magnitude or spread of the plastic-mediated accumulation of chemicals in marine fauna.

To address these knowledge gaps, we used preen gland oil to assess the accumulation of these chemicals in seabirds. Preen gland oil is a wax excreted from an organ situated above the tail of most bird species, including seabirds (Yamashita et al., 2007). Preen gland oil can be collected from live birds and is, therefore, a noninvasive approach that enables sample collection from a wide range of species with minimal interference (Yamashita et al., 2007, Yamashita et al., 2018). Because a previous study suggested that the chemical concentrations in preen gland oil reflect pollution in the internal fat stores of seabirds, preen gland oil can indicate the contaminant burden in the body (Yamashita et al., 2007). Hardesty et al. (2015) demonstrated the utility of this preen oil sampling approach to examine the bioaccumulation of plastic additives (i.e., phthalates) in seabirds. However, Provencher et al. (2020) did not find a relationship between the significant concentrations of phthalate in preen gland oil from northern fulmars and ingested plastic load, raising uncertainty about the utility of this approach. Tanaka et al. (2020b) used the approach to assess BDE209 and three BUVSs in six species of seabirds from Hawaii to demonstrate the accumulation of plastic additives. The present study used this approach to assess BFRs and 6 BUVSs in samples from 145 seabirds, including 32 species from 8 families ( 5 orders), collected from 16 areas across all major ocean basins. To examine the transfer of chemicals from ingested plastics by measuring the additives in the seabird tissues, it is prudent to also consider the potential contaminant contribution from their natural prey as these additives have been detected in marine organisms (e.g., Burreau et al., 2006; Sun et al., 2015; Nakata et al., 2009; Nakata et al., 2010; Nakata et al., 2012; Peng et al., 2017; Lu et al., 2019). To evaluate the accumulation of chemicals through natural prey, we also measured legacy POPs, including polychlorinated biphenyls (PCBs), dichlorodiphenyltricloroethane and its metabolites (DDTs), and hexachlorohexanes (HCHs), which occur in the seabirds' natural prey and can be used as a proxy to assess chemical exposure through diet.

The objectives of the present study were as follows: 1) to understand the magnitude or spread of accumulation of BFRs and BUVSs in the preen gland oil of seabirds and 2) to discuss the relationship between the accumulation of these chemicals, the load of ingested plastic, and the potential contribution from natural prey.

\section{MATERIALS AND METHODS \\ SAMPLING}

We collected preen gland oil from 145 seabirds, which included 32 species from 8 families and 5 orders, between 2008 and 2016 (Fig. 1 and Table S1). Most samples were collected from live birds in their breeding colonies, but 54 were from bird carcasses that were stranded on beaches, caught accidentally in fishing gear, or died because of collisions with infrastructure (Table S1). Live birds were held while their preen glands were wiped to collect oil samples using pre-baked glass-fiber filters or stainless-steel microspatulas, which reduced the chance of contamination. Birds were released immediately after sample collection. For deceased birds, the carcasses were dissected and the preen gland oil samples were collected using a glass-fiber filter. The weight of each collected oil sample was approximately $0.1-50 \mathrm{mg}$ (average: $10 \mathrm{mg}$ ). The glass-fiber filters were wrapped in aluminum foil and the microspatulas were stored in pre-baked glass tubes; they were transported to the laboratory and stored at $-30^{\circ} \mathrm{C}$ until further analysis.

For some carcass samples, ingested plastics were quantified by dissecting the upper gastrointestinal tract (proventriculus and gizzard). The tract was carefully opened with dissecting scissors, and all solid material was rinsed in fresh water over a sieve or into a petri dish. Plastic was separated from natural items, manually counted, patted clean using paper tow$\mathrm{el}$, and air dried before being stored in aluminum foil at room temperature.

\section{CHEMICALS}

Six BUVSs (UV-P, UV-326, UV-329, UV-328, UV-327, and UV-234) were purchased from AccuStandard, Inc. (New Haven, CT, USA). BDE209 and DBDPE were purchased from Wellington Laboratories Inc. (Guelph, ON, Canada). As a running standard of PCBs, a 1:1:1:1 mixture of Kanechlor 300, 400, 500 , and 600 was purchased from GL Science (Tokyo, Japan). The concentrations of individual PCB congeners in the running standard were determined using a gas chromatograph equipped with an ion-trap mass spectrometer. p,p'-DDT, o, $\mathrm{p}^{\prime}$-DDT, $\mathrm{p}, \mathrm{p}^{\prime}$-DDD, o, $\mathrm{p}^{\prime}$-DDD, and p, $\mathrm{p}^{\prime}$-DDE as well as four $\mathrm{HCH}$ isomers $(\alpha, \beta, \gamma$, and $\delta$ ) were purchased from Wako Pure Chemical Industries, Ltd. (Osaka, Japan). As a surrogate standard for PBDEs, 4'-fluoro-2,2',3,3',4,5,5',6,6'-nonabromo-di- 


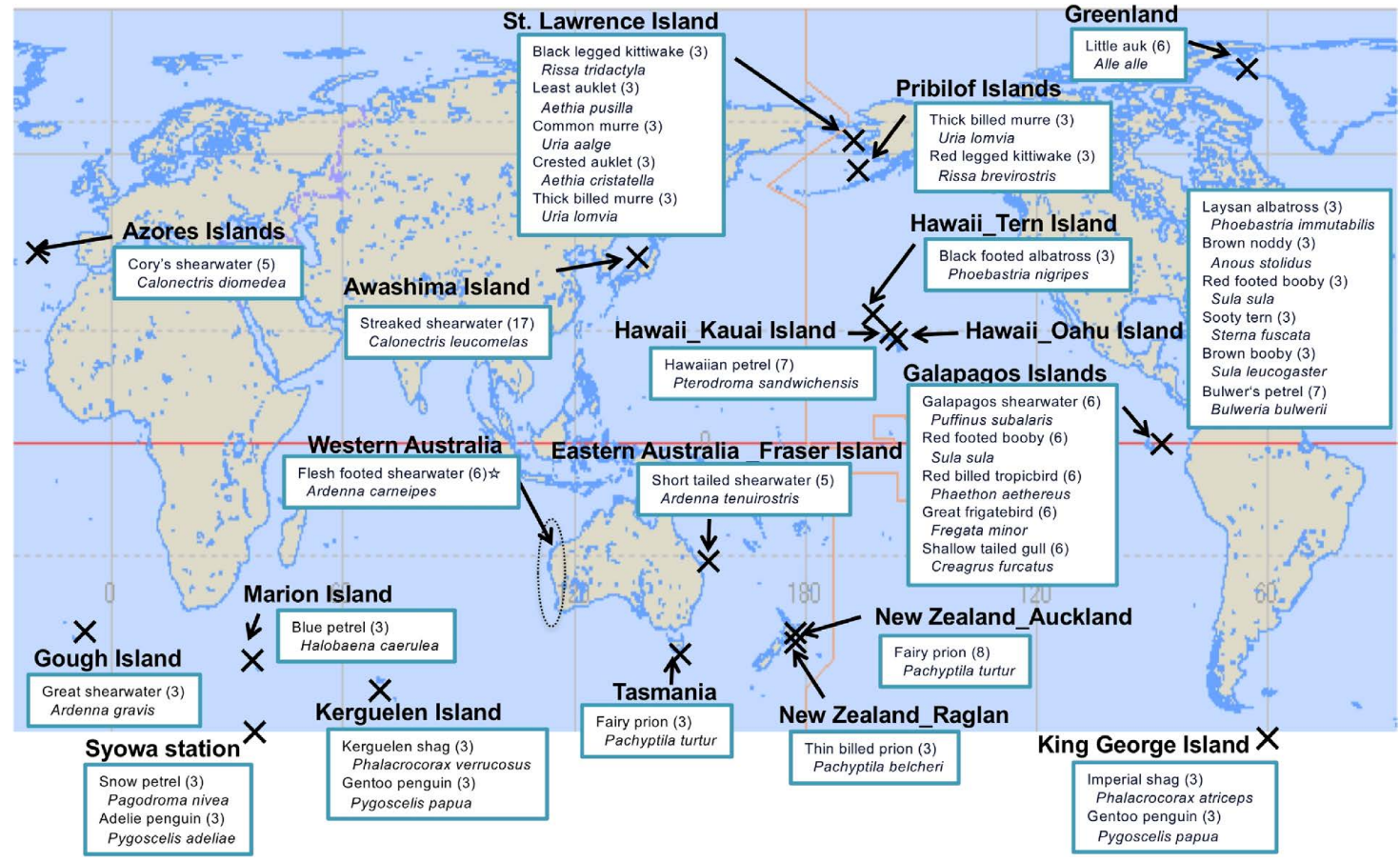

Fig. 1 Seabird preen gland oil sampling locations

phenylether (F-BDE208) was purchased from Wellington Laboratories. As surrogate standards for the UV stabilizers, UV-326- $d_{3}$ and UV-327- $d_{20}$ were purchased from Toronto Research Chemicals (Toronto, ON, Canada) and UV-328- ${ }^{13} C_{6}$ was synthesized under contract with Hayashi Pure Chemical Ind., Ltd. (Osaka, Japan). As internal injection standards, acenaphthene- $d_{8}$ and chrysene- $d_{12}$ were purchased from Sigma-Aldrich (St. Louis, MO, USA). Hexane, acetone, 2,2,4-trimethylpentane (iso-octane), methanol, pyridine, acetic anhydride, hydrochloric acid, anhydrous sodium sulfate, and silica-gel (Wakogel Q-22, through $75 \mu \mathrm{m}$ ) were purchased from Wako Pure Chemical Industries, Ltd. (Osaka, Japan). Dichloromethane (DCM) was purchased from Kanto Chemical Co., Inc. (Tokyo, Japan). Hexane and acetone were distilled in glass. All glass and stainless-steel equipment was rinsed with methanol, acetone, and distilled hexane thrice each or pre-baked at $550^{\circ} \mathrm{C}$ for $4 \mathrm{~h}$.

\section{ANALYTICAL PROCEDURE}

Preen gland oil was extracted using $15 \mathrm{~mL}$ distilled acetone and $n$-hexane $(1: 3, \mathrm{v} / \mathrm{v})$ for $10 \mathrm{~min}$ by sonicating the filter or spatula via an ultrasonic vibrator (SHARP UT-105S, 100W $35 \mathrm{kHz}$ ). This extraction was repeated three times. Combined extracts were spiked with surrogates (f-BDE208, UV-326- $d_{3}$, UV-328- ${ }^{13} C_{6}$, and UV-327- $\left.d_{20}\right)$ and rotary-evaporated to dryness before $4 \mathrm{~mL}$ DCM was added to the extract. One aliquot $(\sim 2$ $\mathrm{mL}$ ) was used to determine lipid weight. The aliquot was evaporated at $100 \mathrm{mmHg}$ on a hot plate at $100^{\circ} \mathrm{C}$ until the weight did not change, and the weight was measured gravimetrically using a chemical balance with a 0.1-mg accuracy. When the weight of the lipid was $<1 \mathrm{mg}$, the lipid weight was measured using Iatroscan (MLK-6, LSI Medience Corporation, Tokyo, Japan) where aliquots of the dried lipid were combusted and the amounts of the generated ions were quantified using a flame ionization detector. To calibrate for quantification, gravi- metrically-measured preen gland oil from short-tailed shearwater (Ardenna tenuirostris) was used. Another aliquot $(\sim 2 \mathrm{~mL})$ was used to measure POPs and additives. The aliquots were subjected to a gel permeation chromatograph column $(2 \mathrm{~cm}$ i.d. $\times 30 \mathrm{~cm}$; CLNpak PAE-2000; Shodex, Japan) to separate target compounds from the biolipids using DCM as an eluent at a flow rate of $4 \mathrm{~mL} / \mathrm{min}$. A fraction of the retention time, from 11.5 to $25 \mathrm{~min}$, was taken, rotary-evaporated to $\sim 0.5 \mathrm{~mL}$, and transferred to a 1.5-mL glass vial. The solvent was evaporated to dryness under a nitrogen stream and $50 \mu \mathrm{L}$ each of pyridine and acetic anhydrate were added. The vial was tightly capped and kept in a sand bath at $45^{\circ} \mathrm{C}$ for $\geq 12 \mathrm{~h}$ to complete acetylation. The reaction was ceased by the addition of $0.2 \mathrm{~mL}$ hydrochloric acid and target compounds were extracted with hexane five times. The hexane extracts were evaporated to dryness and subjected to $10 \% \mathrm{H}_{2} \mathrm{O}$-deactivated silica-gel column chromatography $(1 \mathrm{~cm}$ i.d. $\times 9 \mathrm{~cm})$ with an elution of 30 mL hexane / DCM (3:1, v/v), followed by $30 \mathrm{~mL} \mathrm{DCM}$ with $1 \%$ (v/v) methanol $(\mathrm{MeOH})$. The DCM with $\mathrm{MeOH}$ fraction containing acetylated BUVSs was rotary-evaporated to $\sim 0.5 \mathrm{~mL}$ and transferred to a $1.5-\mathrm{mL}$ glass vial. The solvent was evaporated to dryness under nitrogen stream, and the residue was dissolved in 50-200 $\mu \mathrm{L}$ iso-ocatane with acenaphthene- $d_{8}$ and chrysene- $d_{12}$ as internal injection standards for the measurement of BUVSs on a gas chromatograph equipped with a mass spectrometer (GC-MS; Agilent 7,890A/5,977). The details of the GC-MS conditions are described in Table S2. All BUVSs were measured using the selected ion monitoring mode (Table S3) and quantified based on peak area. The concentrations of UV326, UV327, and UV328 were corrected for the recoveries of the corresponding isotopically-labeled standards, whereas the other BUVSs were not recovery-corrected.

The hexane / DCM (3:1, v/v) fraction of the $10 \% \mathrm{H}_{2} \mathrm{O}$ deactivated silica-gel was further fractionated through a fully acti- 
vated silica-gel column $(0.45 \mathrm{~cm}$ i.d. $\times 18 \mathrm{~cm})$ with $6 \mathrm{~mL}$ hexane (first fraction), $60 \mathrm{~mL}$ hexane (second fraction), and $20 \mathrm{~mL}$ hexane/DCM (3:1, v/v) (third fraction). The second fraction contained PCBs, p,p'-DDE, BDE209, and DBDPE and the third fraction contained p, $\mathrm{p}^{\prime}-\mathrm{DDD}, \quad \mathrm{o}, \mathrm{p}^{\prime}-\mathrm{DDD}, \mathrm{p}, \mathrm{p}^{\prime}-\mathrm{DDT}$, $o, \mathrm{p}^{\prime}$-DDT, and four HCH isomers $(\alpha, \beta, \gamma$, and $\delta)$. The second and third fractions were roto-evaporated to $\sim 0.5 \mathrm{~mL}$, transferred to $1.5-\mathrm{mL}$ vials, further reduced to dryness under gentle nitrogen stream, and redissolved in $50-1,000 \mu \mathrm{L}$ iso-octane for measurements using a gas chromatograph with an electron capture detector (GC-ECD, Agilent 7,890A). PCBs, p,p'-DDE, p,p'-DDD, o,p'-DDD, p,p'-DDT, o,p'-DDT, and $\mathrm{HCH}$ isomers were measured using a 30-m capillary column, whereas BDE209 and DBDPE were measured using a 15-m capillary column. The details of the operating conditions for the instrumental analysis are available in Table S4. Twenty PCB congeners (IUPAC numbers 52, 44, 66/95, 90/101, 110/77, 118, $132 / 153,105,138 / 160,187,128,180,170 / 190$, and 206) were identified and quantified. The sum of their concentrations is expressed as " $\sum_{20}$ PCBs." The sum of p,p'-DDE, p,p'-DDD, o,p'-DDD, p,p'-DDT, and o,p'-DDT is expressed as EDDTs and the sum of the four HCHs isomers $(\alpha, \beta, \gamma$, and $\delta)$ is expressed as $\mathrm{HCH}$. BDE-209 concentration was corrected by the recovery of f-BDE208, whereas no recovery correction was made for DBDPE, PCBs, DDTs, and HCHs.

\section{QUALITY CONTROL AND QUALITY ASSURANCE}

Reproducibility and recovery were confirmed in advance using four replicate analyses of Laysan albatross (Phoebastria immutabilis) adipose tissue extracts with and without spiking of native PCBs, DDTs, HCHs, BFRs and BUVSs standards. The relative standard deviations for the concentrations of the individual congeners were $<10 \%$ and the recoveries were $>83 \%$. A procedural blank using only solvent was run with every analyzed set (5-7 samples). Analytical values less than three times that of the corresponding blanks were considered below the limit of quantification (LOQ). The amount of target compounds in the procedural blank was normally $0.2 \mathrm{ng}$ for UVP, $0.08 \mathrm{ng}$ for UV329, $0.3 \mathrm{ng}$ for UV326, $0.2 \mathrm{ng}$ for UV328, $0.06 \mathrm{ng}$ for UV327, $0.7 \mathrm{ng}$ for UV234, $0.08 \mathrm{ng}$ for $\sum_{20} \mathrm{PCBs}, 0.07 \mathrm{ng}$ for EDDTs, $0.009 \mathrm{ng}$ for $\Sigma \mathrm{HCHs}, 0.02 \mathrm{ng}$ for BDE209, and $0.04 \mathrm{ng}$ for DBDPE. When $10 \mathrm{mg}$ lipid was used for the analysis, LOQ was $70 \mathrm{ng} / \mathrm{g}$-lipid for UVP, $30 \mathrm{ng} / \mathrm{g}$-lipid for UV329, $60 \mathrm{ng} / \mathrm{g}$ lipid for UV326, $50 \mathrm{ng} / \mathrm{g}$-lipid for UV328, $20 \mathrm{ng} / \mathrm{g}$-lipid for UV327, $50 \mathrm{ng} / \mathrm{g}$-lipid for UV234, $30 \mathrm{ng} / \mathrm{g}$-lipid for $\sum_{20} \mathrm{PCBs}, 30$ $\mathrm{ng} / \mathrm{g}$-lipid for EDDTs, $3 \mathrm{ng} / \mathrm{g}$-lipid for $\mathrm{LHCHs}, 3 \mathrm{ng} / \mathrm{g}$-lipid for BDE209, and $8 \mathrm{ng} / \mathrm{g}$-lipid for DBDPE.

\section{DIETARY ANALYSIS}

The main diets of the individual species were estimated using the corresponding references (Snow and Snow, 1968; Bédard, 1969; Harrison et al., 1983; Prince and Morgan, 1987; Williams, 1995; Gaston and Jones, 1998; Brooke, 2004; Nelson, 2005; Spear et al., 2007; Sinclair et al., 2008; Harding et al., 2009; Neves et al., 2012; Raphael et al., 2012; Kokubun et al., 2015) and categorized into five groups: crustaceans (copepods, amphipods, krill, and others), crustaceans and fish, fish, fish and squid, and squid (Table S5).

\section{RESULTS AND DISCUSSION}

To evaluate the sampled seabirds' exposure to chemicals via their natural prey, we have first discussed the concentrations of conventional POPs, i.e., PCBs, DDTs, and HCHs, in the preen gland oil samples.

\section{DISTRIBUTION OF POPS AS A PROXY EXPOSURE PATHWAY TO ANTHROPOGENIC CHEMICALS}

Conventional POPs occurred ubiquitously in the seabird samples; they were detected in $85 \%-94 \%$ of the 145 individuals (Table 1, Table S6). PCBs were the most frequently and abun-

Table 1 Detection of persistent organic pollutants and plastic additives in the preen gland oil of the sampled seabirds

\begin{tabular}{|c|c|c|c|c|}
\hline & $\begin{array}{l}\text { Number of individuals } \\
\text { with additives detected } \\
\text { in their preen gland oil* }\end{array}$ & $\begin{array}{l}\text { Minimum }^{* *} \\
\text { concentration } \\
\text { (ng/g-lipid) }\end{array}$ & $\begin{array}{l}\text { Maximum }^{* *} \\
\text { concentration } \\
\text { (ng/g-lipid) }\end{array}$ & $\begin{array}{l}\text { Median }^{* *} \\
\text { concentration } \\
\text { (ng/g-lipid) }\end{array}$ \\
\hline \multicolumn{5}{|c|}{ Persistent Organic Pollutants (POPS) } \\
\hline$\Sigma 20 \mathrm{PCBs}$ & $137(94 \%)$ & 2 & 21,171 & 102 \\
\hline$\Sigma$ DDTs & $134(92 \%)$ & 2 & 85,712 & 117 \\
\hline$\Sigma \mathrm{HCHs}$ & $122(85 \%)$ & 1 & 927 & 26 \\
\hline \multicolumn{5}{|c|}{ Brominated flame retardants (BFRs) } \\
\hline BDE-209 & $7(5 \%)$ & 3 & 379 & 5 \\
\hline DBDPE & $9(6 \%)$ & 6 & 101 & 20 \\
\hline \multicolumn{5}{|c|}{ Beenzotriazole UV stabilizers (BUVSs) } \\
\hline UVP & $30(21 \%)$ & 14 & 1,789 & 234 \\
\hline UV326 & $19(13 \%)$ & 2 & 129 & 19 \\
\hline UV329 & $34(23 \%)$ & 19 & 4,031 & 133 \\
\hline UV328 & $31(21 \%)$ & 2 & 7,055 & 24 \\
\hline UV327 & $8(6 \%)$ & 1 & 1,852 & 6 \\
\hline UV234 & 27 (19\%) & 5 & 172 & 45 \\
\hline
\end{tabular}

* (percent individuals among 145 studied)

**among significantlly detected 


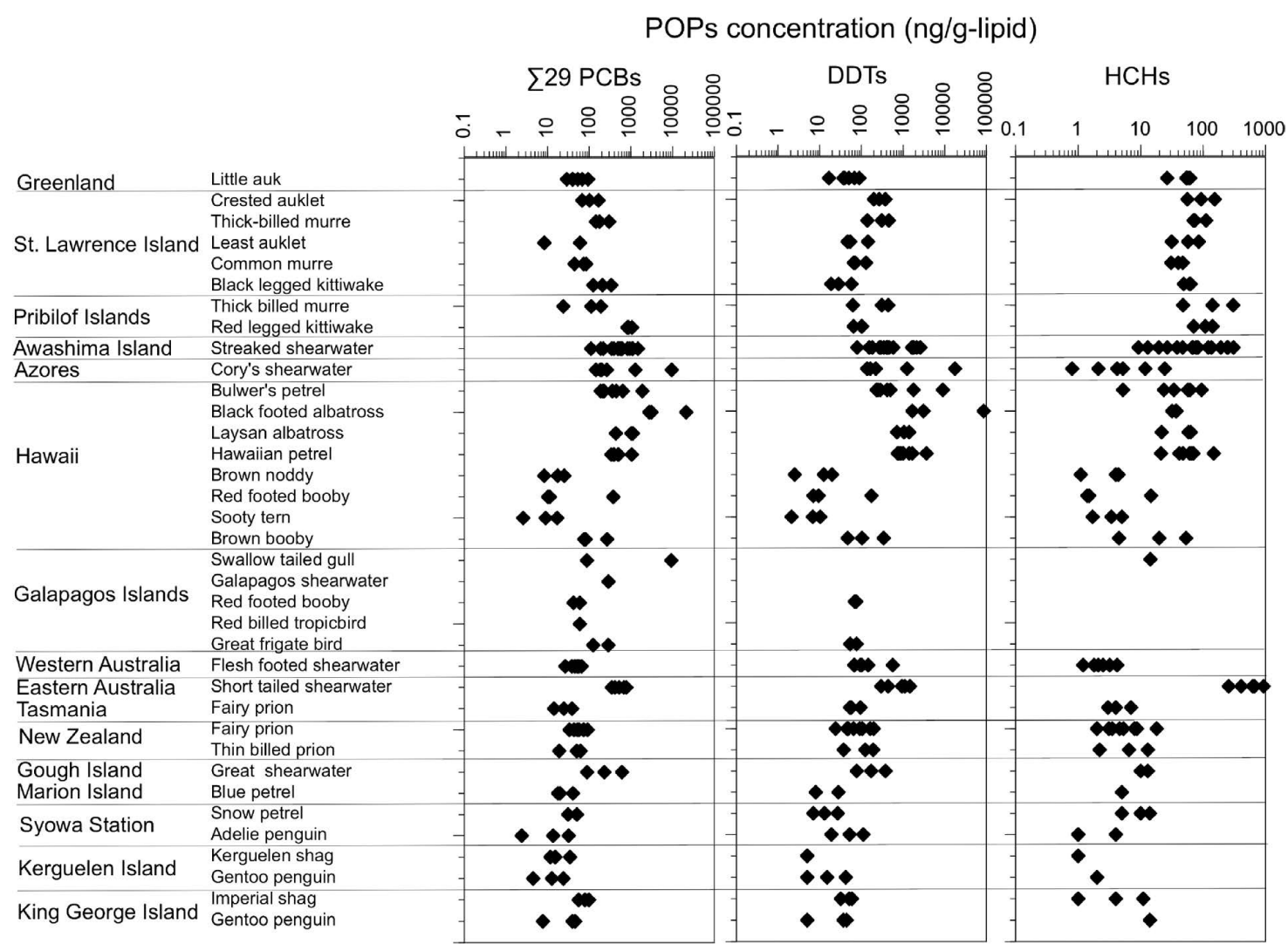

Fig. 2 Concentrations of the (a) PCBs, (b) DDTs, and (c) HCHs in the preen gland oil of the sampled seabirds

dantly detected in these contaminants, with concentrations ranging from 1 to $21,000 \mathrm{ng} / \mathrm{g}$-lipid (median concentration: $102 \mathrm{ng} / \mathrm{g}$-lipid). These results are in accordance with the observations of Yamashita et al. (2018) who reported a range of 2-60,700 ng/g-lipid of PCBs in 154 seabird samples collected across the globe. PCB concentrations reflected the seabird prey and trophic position; they were generally lower for seabirds from the polar regions and the Galápagos Islands (Fig. 2a) and were higher in seabirds that foraged on higher-trophic prey (fish and squids) than those that foraged on crustaceans (Fig. 3). This relationship between PCB concentrations in the preen oil and the trophic position of the seabird's main prey likely results from the biomagnification of PCBs in the food web. This mechanism of biomagnification was evidenced by calculating the ratio of the congeners with different metabolizabilities (CB44, CB110, and CB180). CB44 and CB110 are readily metabolized, whereas $\mathrm{CB} 180$ is more persistent. Thus, the ratio of $(\mathrm{CB} 44+\mathrm{CB} 110)$ to $\mathrm{CB} 180$ should be lower in higher-trophic level seabirds (Yamashita et al., 2007; Yamashita et al., 2018). Seabirds with higher PCB concentrations had lower [(CB44 + CB110) to CB180] ratios (Fig. 4). Among the 12 individuals with $\mathrm{PCB}$ concentrations $>1,000 \mathrm{ng} / \mathrm{g}$-lipid, 9 individuals had a $[(\mathrm{CB} 44+\mathrm{CB} 110)$ to $\mathrm{CB} 180]$ ratio $<0.5$. These taxa included the red-legged kittiwake (Rissa brevirostris), streaked shearwater (Calonectris leucomelas), Cory's shearwater (Calonectris diomedea), black-footed albatross, and Laysan albatross, all of which primarily forage on higher-trophic level prey, such as fish and squid. Moreover, the two albatross species have broad diets, including fishery discards and bait, and regularly scavenge dead organisms, including other seabirds and marine mammals (Gould et al., 1997; Cherel and Klages, 1998).

The spatial distribution patterns of DDTs (Fig. 2b) was similar to that of PCBs. DDT concentrations were lower in the polar regions, with higher concentrations detected in species that forage on higher-trophic prey (Fig. 3). Historically, DDT has been used as a pesticide in agricultural fields while PCBs have been used for industrial purposes. Although both PCBs and DDTs are derived from anthropogenic activities, they differ in their geographical patterns of input into the marine system. Nevertheless, a strong correlation $\left(r^{2}=0.760\right)$ was observed for the concentrations of both compounds in the preen gland oil samples from the species in this study (Fig. 5), suggesting that dietary behavior is a stronger determinant for both DDT and PCB occurrence and concentration in seabirds. In the preen oil samples with higher concentrations of DDTs, DDE was the predominant component. As DDE is a stable metabolite of DDT, a higher proportion of DDE implies that DDT is metabolized by the organisms in the food web. We suggest that the co-occurrence of PCB and DDT concentrations occurs because both compounds are associated with anthropogenic inputs to the ocean and they are similarly biomagnified through the food web.

The spatial pattern of HCHs Fig. 2(c) was similar to that of PCBs and DDTs. Though the correlation between $\mathrm{HCH}$ concentration and PCBs was significant, it was substantially weaker (Fig. $5 ; r^{2}=0.388$ ) than the correlation between PCBs and DDTs $\left(r^{2}=0.760\right)$. This is likely because HCHs are better metabolized by animals (Kennish, 1997) and less biomagnified through the food web than DDTs and PCBs (Schwarzenbach 

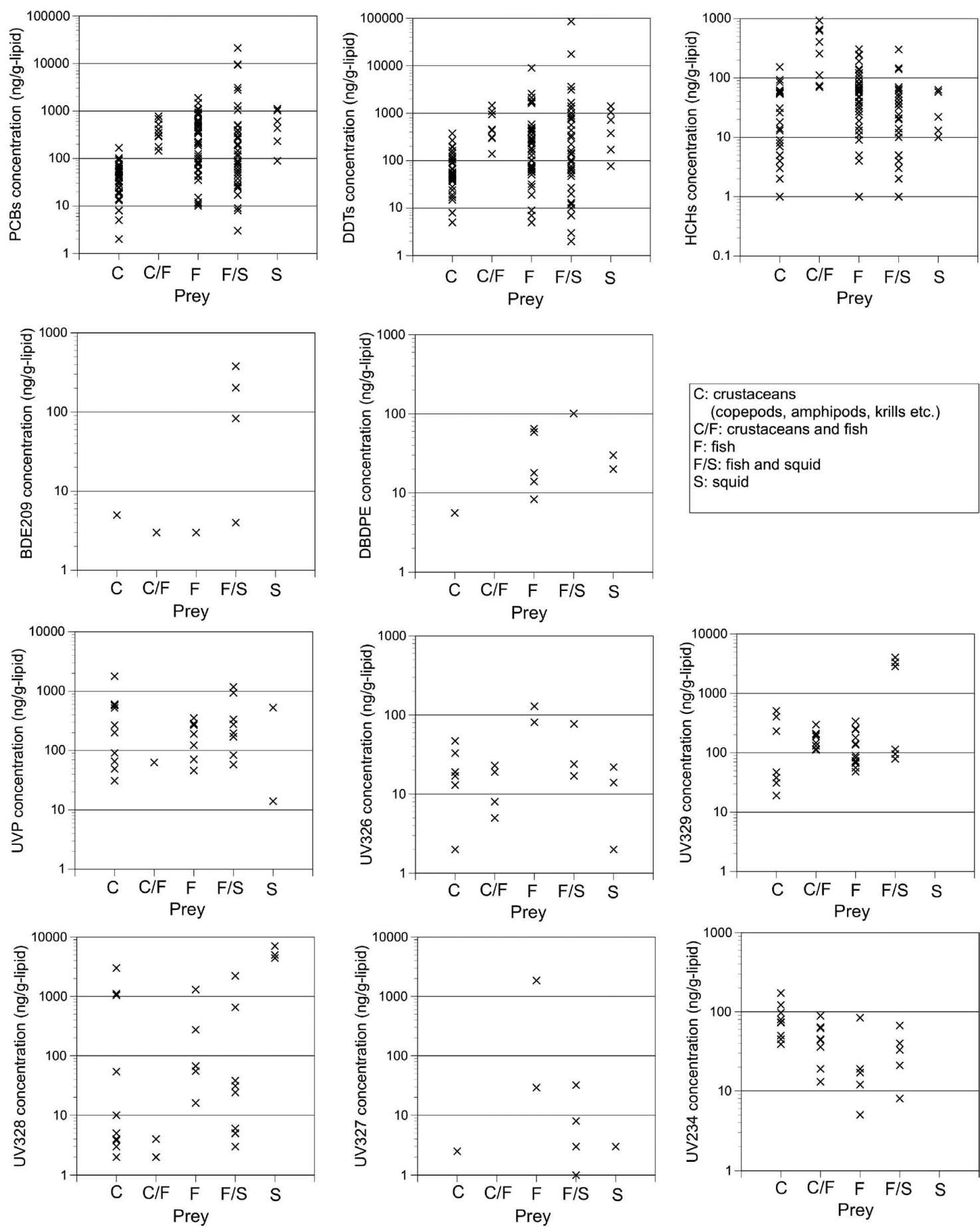

Fig. 3 Concentrations of the legacy POPs and additives in the preen gland oil versus the estimated main diets of the seabirds

et al., 2003). It was also observed that a higher volatility and a resultant susceptibility to aerial transport could contribute to different spatial distributions of HCHs compared with DDTs and PCBs. We found that HCHs were relatively enriched in seabirds from higher latitudes (Fig. 2c), which can be ascribed to global distillation (Wania and MacKay, 1996) owing to the relatively higher volatility of $\mathrm{HCHs}$ and the resultant aerial transport.

\section{PLASTIC ADDITIVES IN PREEN GLAND OIL}

The occurrence pattern of plastic additives differed from that of conventional POPs, with additives occurring more sporadically among the seabird preen oil samples. BDE209 was detected in 7 of the 145 sampled seabirds (Table 1, Fig. 6). The concentration of BDE209 was $83 \mathrm{ng} / \mathrm{g}$-lipid for one Hawaiian petrel (Pterodroma sandwichensis) and 203-379 ng/g-lipid for two great frigatebirds (Fregata minor). All other individuals sampled showed a few $\mathrm{ng} / \mathrm{g}$-lipid or lower concentration. There are two potential routes from where these additives could infiltrate seabird preen gland oil: exposure from ingested plastic and exposure through prey organisms. BDE209 is minimally bioavailable (Burreau et al., 2006; Mizukawa et al., 


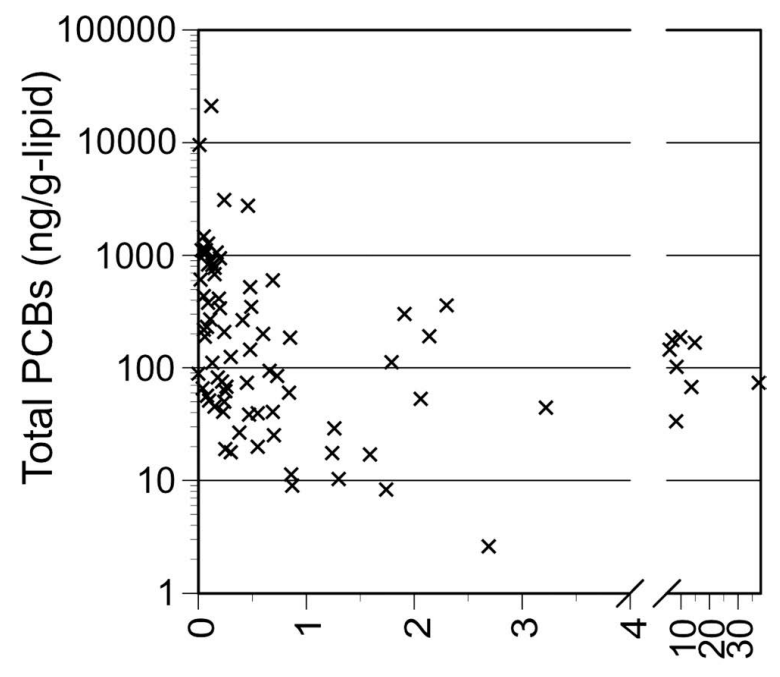

(CB44+CB110)/CB180

Fig. 4 PCB concentrations in the preen gland oil of the sampled seabirds versus the ratio of $(\mathrm{CB} 44+\mathrm{CB} 110)$ to $\mathrm{CB} 180$
2013) because of its high molecular weight and bulky molecular structure. It has been detected in some marine organisms in low concentrations (a few ng / g-lipid or lower, Mizukawa et al., 2013; Sun et al., 2015; Guo et al., 2017); thus, natural prey may account for the low concentrations of BDE209 in some preen gland oil samples (e.g., a few ng / g-lipid for slender-billed prion (Pachyptila belcheri) from New Zealand and Cory's shearwater from the Azores). Because BDE209 is not biomagnified (Burreau et al., 2006; Mizukawa et al., 2013), we believe that the higher concentrations (hundreds ng/g) of BDE209 found in Hawaiian petrels and great frigatebirds are probably derived from ingested plastics. The Hawaiian petrel specimen (sample ID 2013-006) had the highest concentration of BDE 209 (83 ng / g-lipid) and the largest number of ingested plastics (12 pieces) (Table S1). The sporadic detection of plastic additives in the preen gland oil (i.e., 7 of the 145 individuals) is consistent with the sporadic occurrence of BDE209 in the plastic debris. In a previous study that analyzed 194 plastic fragments from seabird stomachs, BDE209 was found in only 1 piece of plastic (0.5\%; Tanaka et al. 2019). This suggests that
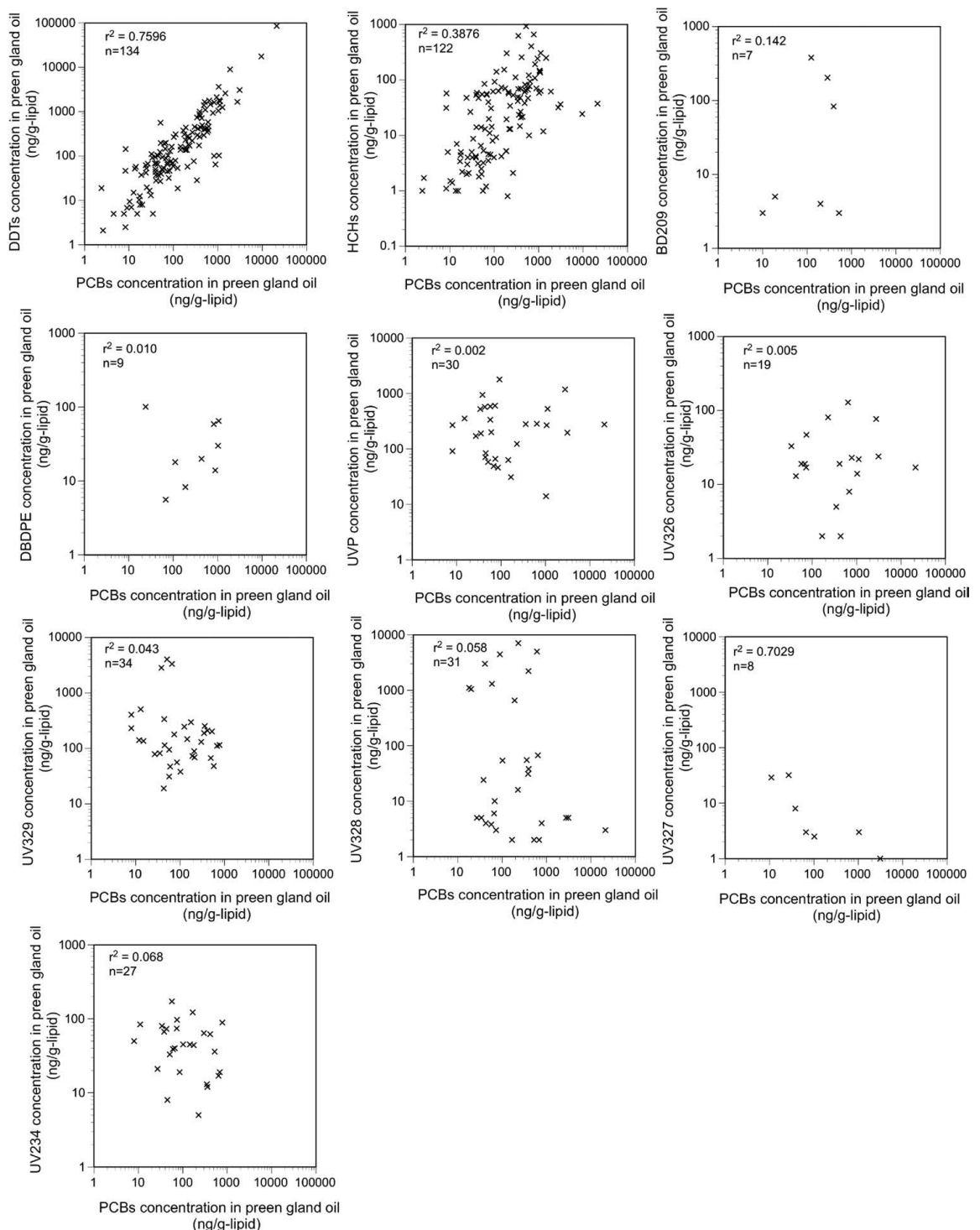

(ng/g-lipid)

(ng/g-lipid)

Fig. 5 Correlation of the contaminant concentrations with PCB concentrations in the preen gland oil of the sampled seabirds. 


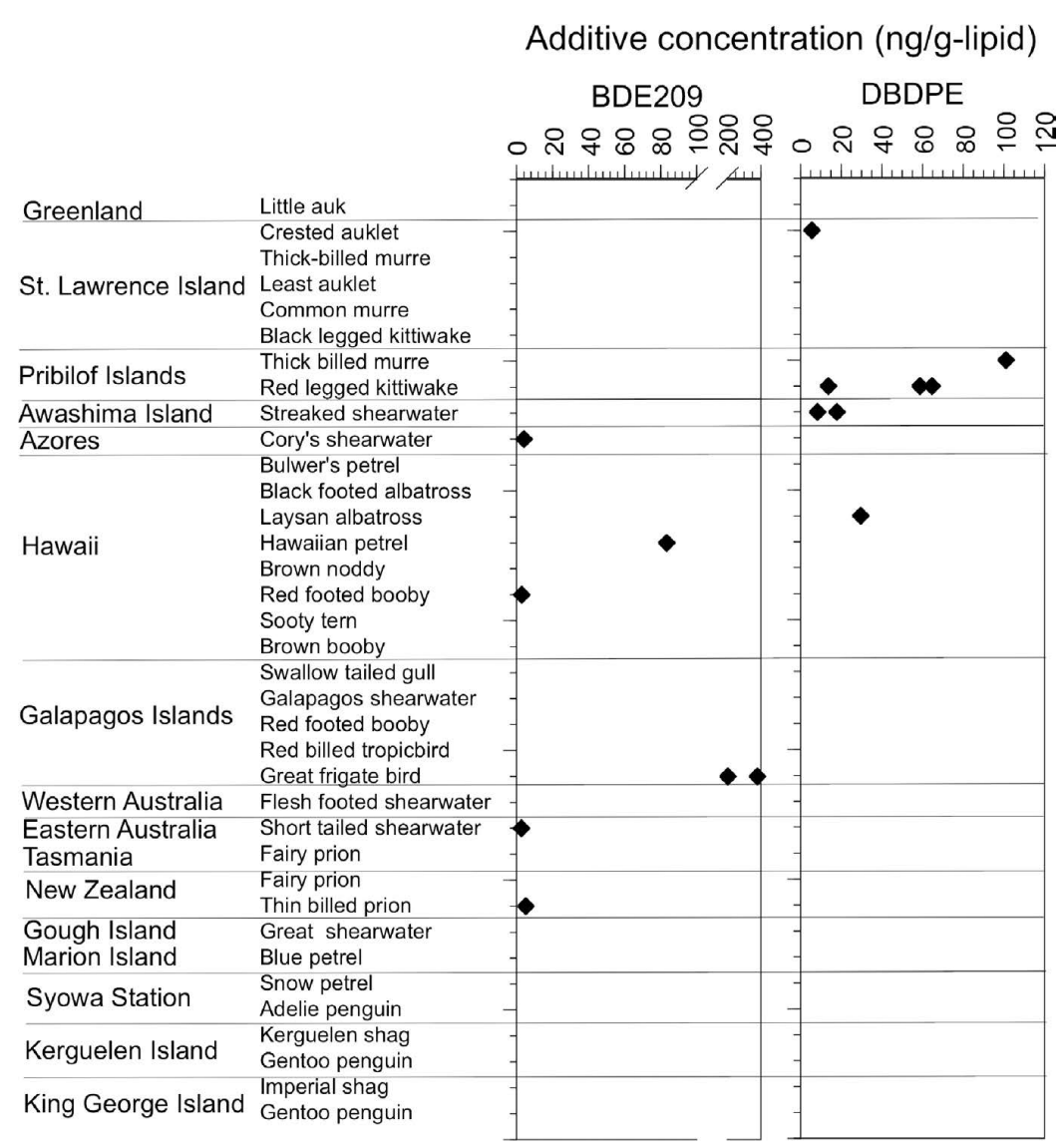

Fig. 6 Brominated flame retardant (BDE209 and DBDPE) concentrations in the preen gland oil of the sampled seabirds

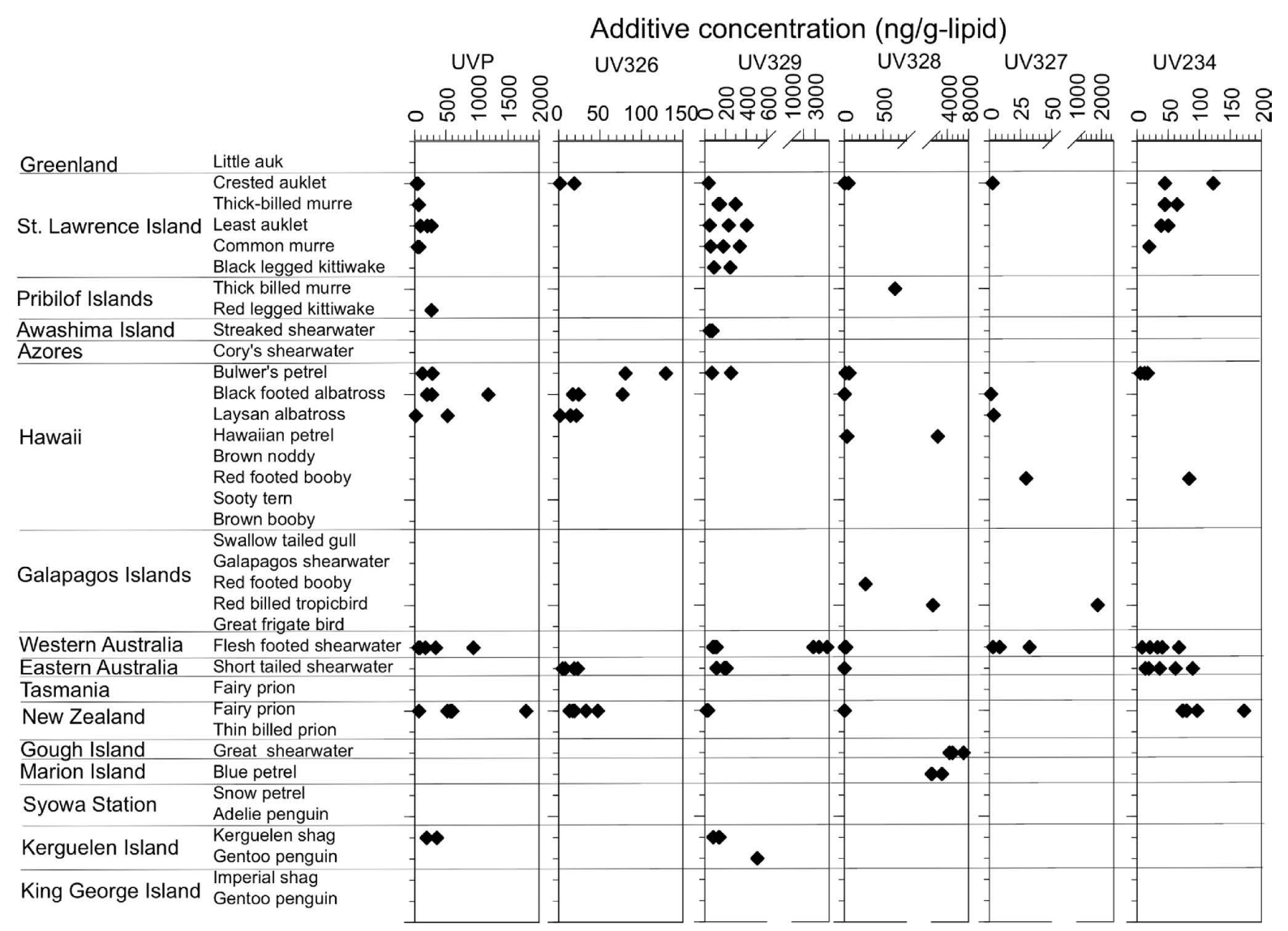

Fig. 7 Benzotriazole-type UV stabilizer (BUVS) concentrations in the preen gland oil of the sampled seabirds 
BFRs are not compounded into all plastic products but only in specific products (e.g., electronics and automobile parts). Plastics ingested by seabirds contained BDE209 at concentrations up to $1.1 \times 10^{6} \mathrm{ng} / \mathrm{g}$ (Tanaka et al., 2019), and the transfer of BDE209 from ingested plastics to preen gland oil has been demonstrated in experimental feeding trials (Tanaka et al., 2020b)

DBDPE also was detected sporadically in only 9 of the 145 individuals sampled (Table 1, Fig. 6). The concentrations of DBDPE were in a similar range $(5.6-101 \mathrm{ng} / \mathrm{g}$ ) as those of BDE209, with the highest concentration (101 ng/g) occurring in a thick-billed murre (Uria lomvia), followed by $14-65 \mathrm{ng} / \mathrm{g}$ in all three red-legged kittiwakes examined (both species sampled at the Pribilof Islands). The bioaccumulation of DBDPE in the food web is also limited because of its higher molecular weight and bulky structure. DBDPE concentrations in aquatic organisms in rural areas were a few ng/g-lipid (Sun et al., 2015). Relatively lower concentrations of DBDPE were present in the preen gland oil of some of the seabirds, such as the streaked shearwater (8.3-18 ng / g-lipid), and we suggest that these contaminants could possibly be derived from natural prey. DBDPE does not reportedly biomagnify in food webs (Zheng et al., 2018), and therefore we suggest that higher DBDPE concentrations may enter seabirds through ingested plastics. Extreme DBDPE concentrations (35-68 ng/g-lipid) have been reported in fishes associated with highly industrial aquatic environments (He et al., 2012). However, the seabird samples containing high DBDPE concentrations in this study were collected in an area far from dense industry, and the foraging areas of these species are largely confined to the Bering Sea. Further support for this conclusion is the lack of high levels of PCBs in individuals with abundant DBDPE (Fig. 5).

BUVSs were also detected sporadically, though more frequently than BFRs. UVP, UV326, UV329, UV328, UV327, and UV234 were detected in 30, 19, 34, 31, 8, and 27 individuals, respectively (Table 1, Fig. 7 ). UV stabilizers as a group were detected in 67 seabirds, which is $46 \%$ of those examined. The sporadic detection of BUVSs is consistent with the occasional occurrence of BUVSs in the plastic fragments on beaches (Tanaka et al., 2020a) and in seabird stomachs (Tanaka et al., 2019), and we suggest that ingested plastics is a key source of exposure to these additives detected in the preen gland oil. The detection frequency of BUVSs (46\%) was significantly higher than that of the two BFRs (11\%). This is likely because UV stabilizers are more widely applied to plastic products than BFRs. The detected concentrations of the individual BUVSs ranged from a few $\mathrm{ng} / \mathrm{g}$ to thousands $\mathrm{ng} / \mathrm{g}$ (Table 1). Considering the results of previous feeding experiments where UV328 and UV326 were demonstrated to transfer from ingested plastics to the preen gland oil in seabirds (Tanaka et al., 2020a), BUVS in the preen gland oil from the wild seabirds is very likely to be a result of leaching from ingested plastics. However, BUVS contributions from their natural prey should also be carefully examined. Target BUVSs are hydrophobic with a $\log \mathrm{K}_{\text {ow }}$ ranging from 5.55 to 7.67 , except for UVP with a $\log \mathrm{K}_{\mathrm{ow}}$ of 3 . The bioaccumulation of BUVSs has been reported in a wide range of marine organisms (Nakata et al., 2009; Nakata et al., 2010; Nakata et al., 2012; Peng et al., 2017; Lu et al., 2019). The concentrations of individual BUVSs in biological tissues across a range of aquatic organisms, including the prey organisms of seabirds, spanned sub ng/g-lipid to hundreds $\mathrm{ng} / \mathrm{g}$-lipid for organisms in an urban estuary in China (Peng et al., 2017), Asian and US west coasts (Nakata et al., 2009; Nakata et al., 2010; Nakata et al., 2012), and Arctic ecosystems (Lu et al., 2019). Among the 53 species examined (including bivalves, crustacean, cephalopods, fishes, seabirds, and seals), the maximum concentrations of the individual BUVSs were as follows: $20 \mathrm{ng} / \mathrm{g}$-lipid for UVP (Peng et al., 2017), $315 \mathrm{ng} / \mathrm{g}$-lipid for UV326 (Lu et al., 2019), $136 \mathrm{ng} / \mathrm{g}$-lipid for UV329 (Lu et al., 2019), $467 \mathrm{ng} / \mathrm{g}$-lipid for UV328 (Nakata et al., 2009), $150 \mathrm{ng}$ / g-lipid for UV327 (Nakata et al., 2009), and $7 \mathrm{ng} / \mathrm{g}$-lipid for UV234 (Peng et al., 2017). These maximum values can be considered as threshold concentrations for BUVSs in seabird preen gland oil, beyond which BUVSs cannot be explained solely by natural prey. Among the 145 individual seabirds we examined, 53 had concentrations of BUVSs exceeding these threshold concentrations, suggesting that natural prey alone is unlikely to explain these high BUV concentrations in preen gland oil. Some BUVSs can be biomagnified, but the effect is not strong (Peng et al., 2017). However, the organisms examined included seabirds and other higher-trophic animals (Lu et al., 2019) and, therefore, the threshold concentrations took biomagnification into account. The other exposure source, i.e.., ingested plastics, must contribute to the high concentrations of BUVSs in these seabird samples.

Unlike PCBs, there was no relationship between the BUVS concentrations and prey organisms (Fig. 3). Furthermore, if the contaminant exposure pathways through prey are the dominant sources for BUVSs in the seabirds, a positive correlation between individual additives and $\mathrm{PCB}$ s would be expected as observed for DDTs and HCHs. This is because both PCBs and BUVSs were derived from anthropogenic activities and similarly hydrophobic and bioaccumulative. However, no positive correlation was found for either additives with PCBs (Fig. 5). Sporadic high BUVS concentrations were detected in seabirds from remote areas where POP concentrations are generally low, resulting in the concentrations of UV329 and UV328 being one to two orders of magnitude higher than those for PCBs. Least auklets (Aethia pusilla) from S.t Lawrence Island had UV329 concentrations of 47-405 $\mathrm{ng} / \mathrm{g}$, whereas their PCB concentration was 8-60 ng/g. Flesh-footed shearwaters (Ardenna carneipes) from Western Australia had UV329 concentrations of 79-4,031 ng/g, whereas their PCB concentration was 27-66 ng / g. Furthermore, great shearwaters (Ardenna gravis) from Gough Island (central South Atlantic Ocean) and blue petrels (Halobaena caerulea) from sub-Antarctic Marion Island (southwest Indian Ocean) had high concentrations of UV-328 (4,987-7,055 ng/ $\mathrm{g}$ and 1,047$3,003 \mathrm{ng} / \mathrm{g}$, respectively), whereas they showed lower PCB concentrations (83-589 $\mathrm{ng} / \mathrm{g}$ and 8-28 $\mathrm{ng} / \mathrm{g}$, respectively; Table S6). This evidence indicates that dietary exposure alone cannot explain the high concentrations of BUVSs detected in the preen gland oil samples from these species.

\section{CASE-EXAMINATION OF PLASTIC INGESTION BY SEABIRDS}

The rate of plastic debris ingestion in seabirds varies among species (Ryan, 2016), within a seabird species range 
and with the regions plastic pollution status (Roman et al., 2019a; Roman et al., 2020b). The load of plastic present in any given individual seabird represents the balance between the ingestion rate and the loss through egestion (both regurgitation and excretion), which is generally poorly understood for most seabird groups (Ryan, 2016). Species-specific considerations, particularly as they relate to foraging strategy and geography, are relevant to consider when determining the likelihood and load of plastic ingested and retained by individual seabirds.

Great shearwaters and blue petrels are the two species with the highest incidence of plastic ingestion in the African sector of the Southern Ocean, with at least $90 \%$ of individuals already containing ingested plastic by the 1980s (Ryan, 1987). Plastic loads have a strong right skew, with most individuals containing only a few plastic items (Ryan, 2016), but some individuals can contain very large amounts of plastic (e.g., a great shearwater contained 194 pieces of plastic, completely filling its ventriculus and most of its proventriculus, Fig. S1). In previous decades there has been a marked shift in the type of plastics that are ingested by these species, from mainly industrial pellets in the 1980s to user plastics fragments post 2000 (Ryan, 2008; Fig. S2). This shift has exposed the birds to increasing levels of plastic additives, and the transfer of BUVSs from the ingested plastics to the seabird tissues is almost certain to occur in this scenario. Great shearwaters are trans-equatorial migrants that feed in the North Atlantic during the boreal summer; the birds sampled in this study were adults on their return to the Southern Hemisphere breeding grounds. Thus, they may have had high levels of ingested plastic (e.g., Ryan, 1987). Blue petrels are a particularly interesting case study as they seldom range outside the Southern Ocean and typically remain in cold water $\left(<10^{\circ} \mathrm{C}\right)$ south of the Antarctic Polar Front. The Southern Ocean contains very low densities of plastics (Suaria et al., 2020), yet blue petrels still ingest and accumulate large plastic loads (Ryan, 1987). Their local (remote) feeding is confirmed by lower concentrations of PCBs (20-41 $\mathrm{ng} / \mathrm{g}$-lipid) than in most of the other seabirds examined in this study. Thus, the dietary exposure of blue petrels to these chemicals in human-impacted areas is unlikely and plastic-mediated exposure in the remote Southern Ocean is the more likely source of the chemicals detected.

Plastic ingestion by flesh-footed shearwaters has been well studied (e.g., Lavers et al., 2014; Lavers et al., 2019; Wilcox et al., 2021), and up to $90 \%$ of fledglings surveyed on Lord Howe Island, off the east coast of Australia, were found to contain ingested plastics. However, plastic ingestion rates are lower in adult birds than in juveniles, and the present study used adult birds only and most samples were from birds from Western Australia. The examined samples were sourced from individuals that had been by-caught in fisheries and were subsequently dissected. Plastic fragments were detected in the stomachs of three birds (WA16-06, WA16-07, and WA16-10), whereas no plastics were found in the other three birds (WA1602, WA16-03, and WA16-04; Table S1). In WA16-07 and WA1610, extremely high concentrations of UV-329 (3,342 and 4,031 $\mathrm{ng} / \mathrm{g}$ ) were detected in the preen gland oil, suggesting that the BUVSs are derived from ingested plastics. Measuring the concentration of additives in the ingested plastics and evaluat- ing the potential ecotoxicological effects caused by BUVSs for these seabirds is recommended in future studies. However, one flesh-footed shearwater (WA16-02) contained a high concentration of UV329 $(2,845 \mathrm{ng} / \mathrm{g})$ in the preen gland oil despite no plastic being found in its stomach. This may be because the plastics were excreted after BUVSs were leached into the bird's system as has previously been reported (Tanaka et al. 2015).

Similar to the great shearwaters, the short-tailed shearwaters from southeastern Australia were sampled shortly after returning south from their northern migration during the northern summer/austral winter. As migration southbound is swift and direct (Carey et al., 2014), ingested plastic/ associated contaminants likely reflect exposure in the North Pacific. Most (88\%) short-tailed shearwaters retain ingested plastic in their gut when traveling south (Roman et al., 2021b). Therefore, the significant detection of multiple additives in the preen gland samples from this species is not unexpected.

Black-footed and Laysan albatrosses feed in the central North Pacific and the Gulf of Alaska and Bering Sea during their breeding season and forage across the North Pacific during their nonbreeding period (Hyrenbach et al., 2002; Kappes et al., 2010; Gutowsky et al., 2014). Plastic ingestion is well documented in both these albatross species in the Hawaiian Islands (Gray et al., 2012; Hyrenbach et al., 2017; Rapp et al., 2017). This may be consistent with the frequent detection of multiple additives, i.e., UVP and UV326, in all six albatrosses examined.

The Hawaiian petrel distribution is more restricted to tropical and subtropical waters around Hawaii compared with the two Hawaiian albatrosses (black-footed and Laysan; Brooke, 2004). Accordingly, PCB concentrations in the preen gland oil were one order of magnitude lower in the petrel (hundreds $\mathrm{ng} / \mathrm{g}$ ) than in the albatrosses (thousands $\mathrm{ng} / \mathrm{g}$ or higher). Yet, despite the lower anticipated impact from anthropogenic pollutants, high concentrations of additives were detected in the preen gland oil from some of the petrel specimens. The occurrence pattern was consistent with the detection of plastics in the digestive tract, as shown in Table S1. All three birds (2013-006; 2013-015; and 2013-017) that contained significant concentrations of an additive had also ingested a larger number of plastics pieces $(9-14)$. By contrast, the other four birds contained no or less plastic pieces $(0-5)$. This pattern can be indicative of the additives derived from the ingested plastics. A lack of the detection of the additives in the preen gland oil of the birds with a smaller but significant number of ingested plastics can be explained by the sporadic occurrence of specific additives in the plastic products (Rani et al., 2017) and fragments (Tanaka et al., 2019), such that no target additives were contained in the specific plastics in their stomachs. This is the first paper to report the plastic ingestion by Hawaiian petrels (Wilcox et al. 2015). Yet, because of the endangered status of this species, the impacts of ingested plastics and associate chemicals require further study.

The Galápagos Islands and surrounding areas are influenced by localized upwelling and characterized by low levels of POPs (Ohgaki et al. 2021). Most Galápagos seabirds have low concentrations of PCBs ( $<100 \mathrm{ng} / \mathrm{g}$-lipid) in their preen gland oil. Samples from red-billed tropicbirds (Phaethon aethereus) 
and great frigatebirds showed significantly high concentrations of UV328 (1,302 ng/g), UV327 (1,852 ng/g), and BDE209 (203 and $379 \mathrm{ng} / \mathrm{g}$ ) in the preen gland oil. Both species forage locally in the Galápagos and the PCB concentrations detected were low ( $<300 \mathrm{ng} / \mathrm{g}$ ); therefore, we suggest that the exposure to chemicals from contaminated prey in an urban coastal zone is unlikely. By contrast, floating plastics were visibly confirmed at the sampling location (Punta/Islote Pitt) of the birds, and both species foraged locally. One hundred and ninety-seven macro plastic items were found in one 50 -m transect at Punta Pitt $\left(0.70844^{\circ} \mathrm{S}, 89.25378^{\circ} \mathrm{W}\right)$ in a recent survey in January 2021. Other seabird colonies contain large amounts of plastics; for example, at El Pescador $\left(0.91719^{\circ} \mathrm{S}, 89.40494^{\circ} \mathrm{W}\right), 4,862$ macro plastic items were recorded in a 50-m transect. These large abundances of plastic in the environment raise concerns regarding their potential impacts on Galápagos marine vertebrates (Muñoz-Pérez, unpublished data) as plastic ingestion has previously been reported in tropicbirds (Madden and Eggermont, 2020). Interestingly, great frigatebirds showed the highest concentrations of BDE209 (203 and $379 \mathrm{ng}$ / g-lipid) among the 145 seabirds examined. These "marauders" forage locally, stealing fish and prey from other birds, and are known to ingest plastic (Rapp et al., 2017); the BUVSs and BFR detected may be derived from secondarily ingested plastics.

As discussed above, higher concentrations of BUVSs are most likely a result of plastic-mediated transfer, whereas lower concentrations of BUVSs might be derived from dietary exposure via their natural prey. Among the 145 individuals examined, 58 seabirds had higher concentrations of BFRs and/or BUVSs than the threshold concentrations, and we posit that $\sim 40 \%$ of the seabirds examined likely accumulated the detected additives from ingested plastics. This estimation largely depends on the threshold concentrations of BUVSs and the two BFRs, i.e., maximum reported concentrations of the additives in the organisms in natural aquatic environments. The detection of higher concentrations ( $>1,000 \mathrm{ng} / \mathrm{g}$ ) of BUVSs in the preen gland oil of great shearwaters from Gough Island, blue petrels from sub-Antarctic Marion Island, black-footed albatrosses and Hawaiian petrels from Hawaii, and flesh-footed shearwaters from Western Australia is consistent with their ingestion of a large number of plastics, as discussed in this section. Thus, we posit that BUVS concentrations exceeding $1,000 \mathrm{ng} / \mathrm{g}$-lipid could be considered a conservative threshold for exposure to ingested plastics. Fourteen seabirds, corresponding to $\sim 10 \%$ of those examined had BUVS concentrations exceeding this conservative threshold (>1,000 ng/g-lipid), and we suggest that they may accumulate additives from many ingested plastics. The remaining $30 \%$ of the seabirds sampled were more likely to have been exposed to plastic additives from a smaller number of plastics or from their natural prey. Distinguishing between both exposures is difficult and a challenge that should be addressed in future studies.

\section{CONCLUSIONS}

Plastic additives were detected sporadically among a range of seabirds from diverse areas around the world. BFR were detected in 16 of the 145 seabirds (11\%), whereas BUVSs were detected in 67 individuals (46\%). High concentrations of addi- tives were detected in seabirds that contained large ingested plastic loads, and this included the great shearwaters from Gough Island, blue petrels from sub-Antarctic Marion Island, black-footed and Laysan albatrosses and Hawaiian petrels from Hawaii, and flesh-footed shearwaters from Western Australia. These occurrence patterns can be explained as the additives are derived mainly from ingested plastics rather than their diet. The detection of BFRs and BUVSs demonstrated that significant portions of the world's seabirds are likely to accumulate chemicals directly from ingesting plastics, but the health consequences of this are not yet fully understood.

\section{ACKNOWLEDGMENTS}

We are grateful to Delia Davies for assistance with the collection of preen gland oil samples and to the South African National Antarctic Programme for logistical and financial support. We also appreciate Harry Burton and Cecilia Eriksson for their support in shipping the samples. The present study was supported by a Grant-in-Aid (Projects No.16H01768, 19H01157, 26550005) and ArCS project supported by the Ministry of Education, Culture, Sports, Science and Technology, Japan.

\section{SUPPLEMENTARY MATERIAL}

Fig. S1, Great Shearwater and plastic fragments found in the stomach (photo: Peter G. Ryan); Fig. S2, Plastic fragments and pellets (bottom right) found in Great Shearwaters on Inaccessible Island, Tristan da Cunha (photo: Peter G. Ryan); Table S1, Sample Information on preen gland oil; Table S2, Instrumental conditions for BUVSs by GC-MS; Table S3, Monitor ion on SIM mode of GC-MS anaysis of BUVSs; Table S4, Instrumental conditions for PCBs, DDTs, and HCHs by GCECD; Table S5, Estimation of main diet of seabird species; Table S6, Additives and POPs concentration in preen gland oil

This material is available on the Website at https://doi. org/10.5985/emcr.20210009.

\section{REFERENCES}

Andrady, A.L., Rajapakse, N., 2017. Additives and chemicals in plastics, In: Takada, H., Karapanagioti, H.K. (eds.), Hazardous chemicals associated with plastics in environment, pp. 1-17, Springer, Berlin Heidelberg, Berlin, Heidelberg. doi: 10.1007/698_2016_124.

Baak, J.E., Linnebjerg, J.F., Barry, T., Gavrilo, M.V., Mallory, M.L., Price, C., Provencher, J.F., 2020a. Plastic ingestion by seabirds in the circumpolar Arctic: a review. Environ. Rev. 28, 506-516. doi: 10.1139/er-2020-0029.

Baak, J.E., Provencher, J.F., Mallory, M.L., 2020b. Plastic ingestion by four seabird species in the Canadian Arctic: comparisons across species and time. Mar. Pollut. Bull. 158, 111386. doi: 10.1016/j.marpolbul.2020.111386.

Bédard, J., 1969. Feeding of the least, crested, and parakeet auklets around St. Lawrence Island, Alaska. Can. J. Zool. 47, 1025-1050. doi: 10.1139/z69-166.

Brooke, M., 2004. Albatrosses and Petrels Across the World: Procellariidae (bird families of the world). Oxford University Press, New York.

Burreau, S., Zebuihr, Y., Broman, D., Ishaq, R., 2006. Biomagnification of PBDEs and PCbs in food webs from the Baltic Sea 
and the northern Atlantic Ocean. Sci. Total Environ. 366, 659-672. doi: 10.1016/j.scitotenv.2006.02.005.

Carey, M.J., Phillips, R.A., Silk, J.R.D., Shaffer, S.A., 2014. Trans-equatorial migration of Short-tailed Shearwaters revealed by geolocators. Emu. Austral. Ornithol. 114, 352-359. doi: 10.1071/MU13115.

Cherel, Y., Klages, N., 1998. A review of the food of albatrosses, In: Robertson, G., Gales, R. (eds.), Albatross biology and conservation, pp. 113-136, Surrey Beatty \& Sons, Chipping Norton.

ECHA, 2020. Estimating the number and types of applications for 11 substances added to the Authorisation List, in February 2020. https://echa.europa.eu/documents/10162/13634/ applications_for_11_substances_Authorisation_List_ February_2020.pdf/66fd8424-5f57-9c33-f3e5-265f01f754ba (accessed 12 September 2021)

Eriksen, M., Lebreton, L.C.M., Carson, H.S., Thiel, M., Moore, C.J., Borerro, J.C., Galgani, F., Ryan, P.G., Reisser, J., 2014. Plastic pollution in the world's oceans: more than 5 trillion plastic pieces weighing over 250,000 tons afloat at sea. PLOS ONE 9, e111913. doi: 10.1371/journal.pone.0111913.

Feng, H., Cao, H., Li, J., Zhang, H., Xue, Q., Liu, X., Zhang, A., Fu, J., 2020. Estrogenic activity of benzotriazole UV stabilizers evaluated through in vitro assays and computational studies. Sci. Total Environ. 727, 138549. doi: 10.1016/j.scitotenv.2020. 138549.

Gaston, A., Jones, I., 1998. Bird families of the world: the auks. Oxford University Press, New York.

Geyer, R., Jambeck, J.R., Law, K.L., 2017. Production, use, and fate of all plastics ever made. Sci. Adv. 3, e1700782. doi: 10.1126/sciadv.1700782.

Gould, P.J., Ostrom, P., Walker, W., 1997. Trophic relationships of albatrosses associated with squid and large-mesh driftnet fisheries in the North Pacific Ocean. Can. J. Zool. 75, 549562. https://cdnsciencepub.com/doi/10.1139/z97-068. doi: 10.1139/z97-068.

Gray, H., Lattin, G.L., Moore, C.J., 2012. Incidence, mass and variety of plastics ingested by Laysan (Phoebastria immutabilis) and Black-footed Albatrosses (P. nigripes) recovered as by-catch in the North Pacific Ocean. Mar. Pollut. Bull. 64, 2190-2192. doi: 10.1016/j.marpolbul.2012.07.053.

Guo, J., Venier, M., Salamova, A., Hites, R.A., 2017. Bioaccumulation of Dechloranes, organophosphate esters, and other flame retardants in Great Lakes fish. Sci. Total Environ. 583, 1-9. doi: 10.1016/j.scitotenv.2016.11.063.

Gutowsky, S.E., Gutowsky, L.F.G., Jonsen, I.D., Leonard, M.L., Naughton, M.B., Romano, M.D., Shaffer, S.A., 2014. Daily activity budgets reveal a quasi-flightless stage during non-breeding in Hawaiian albatrosses. Mov. Ecol. 2, 23. doi: 10.1186/s40462-014-0023-4.

Hardesty, B.D., Holdsworth, D., Revill, A.T., Wilcox, C., 2015. A biochemical approach for identifying plastics exposure in live wildlife. Methods Ecol. Evol. 6, 92-98. doi: 10.1111/2041210X.12277.

Harding, A.M.A., Egevang, C., Walkusz, W., Merkel, F., Blanc, S., Grémillet, D., 2009. Estimating prey capture rates of a planktivorous seabird, the little auk (Alle alle), using diet, diving behaviour, and energy consumption. Polar Biol. 32, 785-796. doi: 10.1007/s00300-009-0581-x.
Harrison, C.S., Hida, T.S., Seki, M.P., 1983. Hawaiian seabird feeding ecology. Wildl. Monogr., 3-71. https://www.jstor. org/stable/3830593.

He, M.J., Luo, X.J., Chen, M.Y., Sun, Y.X., Chen, S.J., Mai, B.X., 2012. Bioaccumulation of polybrominated diphenyl ethers and decabromodiphenyl ethane in fish from a river system in a highly industrialized area, South China. Sci. Total Environ. 419, 109-115. doi: 10.1016/j.scitotenv.2011.12.035.

Hirai, H., Takada, H., Ogata, Y., Yamashita, R., Mizukawa, K., Saha, M., Kwan, C., Moore, C., Gray, H., Laursen, D., Zettler, E.R., Farrington, J.W., Reddy, C.M., Peacock, E.E., Ward, M.W., 2011. Organic micropollutants in marine plastics debris from the open ocean and remote and urban beaches. Mar. Pollut. Bull. 62, 1683-1692. doi: 10.1016/j.marpolbul. 2011.06.004.

Hyrenbach, K.D., Fernández, P., Anderson, D., 2002. Oceanographic habitats of two sympatric North Pacific albatrosses during the breeding season. Mar. Ecol. Prog. Ser. 233, 283301. doi: $10.3354 /$ meps 233283 .

Hyrenbach, K.D., Hester, M.M., Adams, J., Titmus, A.J., Michael, P., Wahl, T., Chang, C.-W., Marie, A., Vanderlip, C., 2017. Plastic ingestion by Black-footed albatross Phoebastria nigripes from Kure Atoll, Hawai'i: Linking chick diet remains and parental at-sea foraging distributions. Mar. Ornithol. 45, 225-236. http://www.marineornithology.org/content/ get.cgi? rn=1232.

Jambeck, J.R., Geyer, R., Wilcox, C., Siegler, T.R., Perryman, M., Andrady, A., Narayan, R., Law, K.L., 2015. Marine pollution. Plastic waste inputs from land into the ocean. Science 347, 768-771. doi: 10.1126/science.1260352.

Jâms, I.B., Windsor, F.M., Poudevigne-Durance, T., Ormerod, S.J., Durance, I., 2020. Estimating the size distribution of plastics ingested by animals. Nat. Commun. 11, 1594. doi: 10.1038/s41467-020-15406-6.

Kappes, M.A., Shaffer, S.A., Tremblay, Y., Foley, D.G., Palacios, D.M., Robinson, P.W., Bograd, S.J., Costa, D.P., 2010. Hawaiian albatrosses track interannual variability of marine habitats in the North Pacific. Prog. Oceanogr. 86, 246-260. doi: 10.1016/j.pocean.2010.04.012.

Kennish, M.J., 1997. Practical handbook of estuarine and marine pollution, 1st ed. CRC Press Press, FL.

Kokubun, N., Yamamoto, T., Kikuchi, D.M., Kitaysky, A., Takahashi, A., 2015. Nocturnal foraging by red-legged kittiwakes, a surface feeding seabird that relies on deep water prey during reproduction. PLOS ONE 10, e0138850. doi: 10.1371/journal.pone.0138850.

Kühn, S., Booth, A.M., Sørensen, L., van Oyen, A., van Franeker, J.A., 2020. Transfer of additive chemicals from marine plastic debris to the stomach oil of northern fulmars. Front. Environ. Sci. 8. doi: 10.3389/fenvs.2020.00138.

Kühn, S., van Franeker, J.A., 2020. Quantitative overview of marine debris ingested by marine megafauna. Mar. Pollut. Bull. 151, 110858. doi: 10.1016/j.marpolbul.2019.110858.

Lavers, J.L., Bond, A.L., Hutton, I., 2014. Plastic ingestion by Flesh-footed Shearwaters (Puffinus carneipes): implications for fledgling body condition and the accumulation of plastic-derived chemicals. Environ. Pollut. 187, 124-129. doi: 10.1016/j.envpol.2013.12.020.

Lavers, J.L., Hutton, I., Bond, A.L., 2019. Clinical Pathology of 
Plastic Ingestion in Marine Birds and Relationships with Blood Chemistry. Environ. Sci. Technol. 53, 9224-9231. doi: 10.1021/acs.est.9b02098.

Lu, Z., De Silva, A.O., Provencher, J.F., Mallory, M.L., Kirk, J.L., Houde, M., Stewart, C., Braune, B.M., Avery-Gomm, S., Muir, D.C.G., 2019. Occurrence of substituted diphenylamine antioxidants and benzotriazole UV stabilizers in Arctic seabirds and seals. Sci. Total Environ. 663, 950-957. doi: 10.1016/j.scitotenv.2019.01.354.

Madden, H., Eggermont, E., 2020. First evidence of plastic ingestion by Red-billed Tropicbirds Phaethon aethereus from St. Eustatius, Caribbean Netherlands. Mar. Ornithol. 48, 157-160. http://www.marineornithology.org/PDF/48_2/48_2_157160.pdf

McDonald,T.A., 2002.A perspective on the potential health risks of PBDEs. Chemosphere 46, 745-755. doi: 10.1016/S00456535(01)00239-9.

Mizukawa, K., Yamada, T., Matsuo, H., Takeuchi, I., Tsuchiya, K., Takada, H., 2013. Biomagnification and debromination of polybrominated diphenyl ethers in a coastal ecosystem in Tokyo Bay. Sci. Total Environ. 449, 401-409. doi: 10.1016/j. scitotenv.2013.01.092.

Nagayoshi, H., Kakimoto, K., Takagi, S., Konishi, Y., Kajimura, K., Matsuda, T., 2015. Benzotriazole ultraviolet stabilizers show potent activities as human aryl hydrocarbon receptor ligands. Environ. Sci. Technol. 49, 578-587. doi: 10.1021/ es503926w.

Nakari, T., Huhtala, S., 2010. In vivo and in vitro toxicity of decabromodiphenyl ethane, a flame retardant. Environ. Toxicol. 25, 333-338. doi: 10.1002/tox.20499.

Nakata, H., Murata, S., Filatreau, J., 2009. Occurrence and concentrations of benzotriazole UV stabilizers in marine organisms and sediments from the Ariake Sea, Japan. Environ. Sci. Technol. 43, 6920-6926. doi: 10.1021/es900939j.

Nakata, H., Shinohara, R.-I., Murata, S., Watanabe, M., 2010. Detection of benzotriazole UV stabilizers in the blubber of marine mammals by gas chromatography-high resolution mass spectrometry (GC-HRMS). J. Environ. Monit. 12, 20882092. doi: 10.1039/C0EM00170H.

Nakata, H., Shinohara, R.-I., Nakazawa, Y., Isobe, T., Sudaryanto, A., Subramanian, A., Tanabe, S., Zakaria, M.P., Zheng, G.J., Lam, P.K.S., Kim, E.Y., Min, B.Y., We, S.U., Viet, P.H., Tana, T.S., Prudente, M., Frank, D., Lauenstein, G., Kannan, K., 2012. Asia-Pacific mussel watch for emerging pollutants: distribution of synthetic musks and benzotriazole UV stabilizers in Asian and US coastal waters. Mar. Pollut. Bull. 64, 22112218. doi: 10.1016/j.marpolbul.2012.07.049.

Nelson, B., 2005. Pelicans, cormorants, and their relatives. Oxford University Press, New York.

Neves, V., Nolf, D., Clarke, M., 2012. Spatio-temporal variation in the diet of Cory's shearwater Calonectris diomedea in the Azores Archipelago, northeast Atlantic. Deep Sea Res. 70, 1-13. doi: 10.1016/j.dsr.2012.08.003.

Ohgaki, T., Takada, H., Yoshida, R., Mizukawa, K., Yeo, B.G., Alidoust, M., Hirai, N., Yamashita, R., Tokumaru, T., Watanabe, I., Onwona-Agyeman, S., Gardiner, P., Eriksen, M., Kelly, J.F., Rodríguez-Sierra, C.J., Colasse, L., Baztan, J., Barretto, F.P., Mendes, G.I., Abessa, D., Zakaria, M.P., Kwan, C.S., Saha, M., Ryan, P.G., Weerts, S., Ofosu-Anim, J., Sabi,
E.B., Akita, L.G., Tait, H., Eriksson, C., Burton, H., 2021. International Pellet Watch: global monitoring of polybrominated diphenyl ethers (PBDEs) in plastic resin pellets. Environ. Monit. Contam. Res. 1, 75-90. doi: 10.5985/emcr.20210002.

Peng, X., Fan, Y., Jin, J., Xiong, S., Liu, J., Tang, C., 2017. Bioaccumulation and biomagnification of ultraviolet absorbents in marine wildlife of the Pearl River Estuarine, South China Sea. Environ. Pollut. 225, 55-65. doi: 10.1016/j.envpol.2017. 03.035.

Persistent organic pollutants review committee, 2021. Report of the Persistent Organic Pollutants Review Committee on the work of its sixteenth meeting, p. 25. http://chm.pops. int/TheConvention / POPsReviewCommittee / Meetings / POPRC16/Overview/tabid / 8472/Default.aspx (accessed 16 September 2021)

Pierce, K.E., Harris, R.J., Larned, L.S., Pokras, M.A., 2004. Obstruction and starvation associated with plastic ingestion in a Northern gannet Morus bassanus and a Greater shearwater Puffinus gravis. Mar. Ornithol. 32, 187-189. http://www. marineornithology.org/PDF/32_2/32_2_187-189.pdf

Prince, P.A., Morgan, R.A., 1987. Diet and feeding ecology of Procel lariiformes, In: JP, C. (eds.), Seabirds feeing ecology and role in marine ecosystems, pp 135-171, Cambridge University Press, Cambridge.

Provencher, J.F., Avery-Gomm, S., Braune, B.M., Letcher, R.J., Dey, C.J., Mallory, M.L., 2020. Are phthalate ester contaminants in northern fulmar preen oil higher in birds that have ingested more plastic? Mar. Pollut. Bull. 150, 110679. doi: 10.1016/j.marpolbul.2019.110679.

Rani, M., Shim, W.J., Han, G.M., Jang, M., Song, Y.K., Hong, S.H., 2017. Benzotriazole-type ultraviolet stabilizers and antioxidants in plastic marine debris and their new products. Sci. Total Environ. 579, 745-754. doi: 10.1016/j.scitotenv.2016.11. 033.

Raphael, A.L., Jean-François, R., David, R.S.L., 2012. Diet Composition of Seabirds from Corossol Island, Canada, Using Direct Dietary and Stable Isotope Analyses. Waterbirds 35, 402-419. doi: 10.1675/063.035.0305.

Rapp, D.C., Youngren, S.M., Hartzell, P., David Hyrenbach, K., 2017. Community-wide patterns of plastic ingestion in seabirds breeding at French Frigate Shoals, Northwestern Hawaiian Islands. Mar. Pollut. Bull. 123, 269-278. doi: 10.1016/ j.marpolbul.2017.08.047.

Roman, L., Bell, E., Wilcox, C., Hardesty, B.D., Hindell, M., 2019a. Ecological drivers of marine debris ingestion in procellariiform seabirds. Sci. Rep. 9, 916. doi: 10.1038/s41598018-37324-w.

Roman, L., Butcher, R.G., Stewart, D., Hunter, S., Jolly, M., Kowalski, P., Hardesty, B.D., Lenting, B., 2021a. Plastic ingestion is an underestimated cause of death for southern hemisphere albatrosses. Conserv. Lett. 14, e12785. doi: 10.1111/conl.12785.

Roman, L., Bryan, S., Bool, N., Gustafson, L., Townsend, K., 2021b. Desperate times call for desperate measures: nonfood ingestion by starving seabirds. Mar. Ecol. Prog. Ser. 662, 157-168. doi: 10.3354/meps13626.

Roman, L., Hardesty, B.D., Hindell, M.A., Wilcox, C., 2019b. A quantitative analysis linking seabird mortality and marine debris ingestion. Sci. Rep. 9, 3202. doi: 10.1038/s41598-018- 
36585-9.

Roman, L., Hardesty, B.D., Hindell, M.A., Wilcox, C., 2020a. Disentangling the influence of taxa, behaviour and debris ingestion on seabird mortality. Environ. Res. Lett. 15, 124071. doi: 10.1088/1748-9326/abcc8e.

Roman, L., Kastury, F., Petit, S., Aleman, R., Wilcox, C., Hardesty, B.D., Hindell, M.A., 2020b. Plastic, nutrition and pollution; relationships between ingested plastic and metal concentrations in the livers of two Pachyptila seabirds. Sci. Rep. 10, 18023. doi: 10.1038/s41598-020-75024-6.

Roman, L., Paterson, H., Townsend, K.A., Wilcox, C., Hardesty, B.D., Hindell, M.A., 2019c. Size of marine debris items ingested and retained by petrels. Mar. Pollut. Bull. 142, 569575. doi: 10.1016/j.marpolbul.2019.04.021.

Ryan, P.G., 1987. The incidence and characteristics of plastic particles ingested by seabirds. Mar. Environ. Res. 23, 175206. doi: 10.1016/0141-1136(87)90028-6.

Ryan, P.G., 2008. Seabirds indicate changes in the composition of plastic litter in the Atlantic and south-western Indian Oceans. Mar. Pollut. Bull. 56, 1406-1409. doi: 10.1016/j. marpolbul.2008.05.004.

Ryan, P.G., 2016. Ingestion of plastics by marine organisms, In: Takada, H., Karapanagioti, H.K. (eds.), Hazardous chemicals associated with plastics in the marine environment, pp. 235-266, Springer International Publishing, Cham. doi: 10.1007/698_2016_21.

Sakuragi, Y., Takada, H., Sato, H., Kubota, A., Terasaki, M., Takeuchi, S., Araki, A., Watanabe, Y., Kitamura, S., Kojima, H., 2021. An analytical survey of benzotriazole UV stabilizers in plastic products and their endocrine-disrupting potential via human estrogen and androgen receptors. Sci. Total Environ. 800, 149374. doi: 10.1016/j.scitotenv.2021.149374.

Schwarzenbach, R.P., Gschwend, P.M., Imboden, D.M., 2003. Environmental organic chemistry, John Wiley \& Sons, Inc., NJ.

Sinclair, E.H., Vlietstra, L.S., Johnson, D.S., Zeppelin, T.K., Byrd, G.V., Springer, A.M., Ream, R.R., Hunt, G.L., 2008. Patterns in prey use among fur seals and seabirds in the Pribilof Islands. Deep Sea Res. II 55, 1897-1918. doi: 10.1016/j. dsr2.2008.04.031.

Snow, B.K., Snow, D.W., 1968. Behavior of the swallow-tailed gull of the Galapagos. Condor 70, 252-264. doi: 10.2307/ 1366698 .

Spear, L.B., Ainley, D.G., Walker, W.A., 2007. Foraging dynamics of seabirds in the eastern tropical Pacific Ocean. Cooper Ornithological Society, Norman, OK.

Suaria, G., Perold, V., Lee, J.R., Lebouard, F., Aliani, S., Ryan, P.G., 2020. Floating macro- and microplastics around the Southern Ocean: results from the Antarctic Circumnavigation Expedition. Environ. Int. 136, 105494. doi: 10.1016/j.envint. 2020.105494.

Sun, B., Hu, Y., Cheng, H., Tao, S., 2019. Releases of brominated flame retardants (BFRs) from microplastics in aqueous medium: kinetics and molecular-size dependence of diffusion. Water Res. 151, 215-225. doi: 10.1016/j.watres.2018. 12.017.

Sun, Y.X., Zhang, Z.W., Xu, X.R., Hu, Y.X., Luo, X.J., Cai, M.G., Mai, B.X., 2015. Bioaccumulation and biomagnification of halogenated organic pollutants in mangrove biota from the
Pearl River Estuary, South China. Mar. Pollut. Bull. 99, 150156. doi: 10.1016/j.marpolbul.2015.07.041.

Tanaka, K., Takada, H., Ikenaka, Y., Nakayama, S.M.M., Ishizuka, M., 2020a. Occurrence and concentrations of chemical additives in plastic fragments on a beach on the island of Kauai, Hawaii. Mar. Pollut. Bull. 150, 110732. doi: 10.1016/j.marpolbul.2019.110732.

Tanaka, K., Takada, H., Yamashita, R., Mizukawa, K., Fukuwaka, M.A., Watanuki, Y., 2015. Facilitated leaching of additive-derived PBDEs from plastic by seabirds' stomach oil and accumulation in tissues. Environ. Sci. Technol. 49, 11799-11807. doi: 10.1021/acs.est.5b01376.

Tanaka, K., van Franeker, J.A., Deguchi, T., Takada, H., 2019. Piece-by-piece analysis of additives and manufacturing byproducts in plastics ingested by seabirds: implication for risk of exposure to seabirds. Mar. Pollut. Bull. 145, 36-41. doi: 10.1016/j.marpolbul.2019.05.028.

Tanaka, K., Watanuki, Y., Takada, H., Ishizuka, M., Yamashita, R., Kazama, M., Hiki, N., Kashiwada, F., Mizukawa, K., Mizukawa, H., Hyrenbach, D., Hester, M., Ikenaka, Y., Nakayama, S.M.M., 2020b. In vivo accumulation of plastic-derived chemicals into seabird tissues. Curr. Biol. 30, 723-728.e3. doi: 10.1016/j. cub.2019.12.037.

Tanaka, K., Yamashita, R., Takada, H., 2018. Transfer of hazardous chemicals from ingested plastics to higher-trophic-level organisms, In: Takada, H., Karapanagioti, H.K. (eds.), Hazardous chemicals associated with plastics in the marine environment, pp. 267-280, Springer International Publishing, Cham. doi: 10.1007/698_2018_255.

Teuten, E.L., Saquing, J.M., Knappe, D.R.U., Barlaz, M.A., Jonsson, S., Björn, A., Rowland, S.J., Thompson, R.C., Galloway, T.S., Yamashita, R., Ochi, D., Watanuki, Y., Moore, C., Viet, P.H., Tana, T.S., Prudente, M., Boonyatumanond, R., Zakaria, M.P., Akkhavong, K., Ogata, Y., Hirai, H., Iwasa, S., Mizukawa, K., Hagino, Y., Imamura, A., Saha, M., Takada, H., 2009. Transport and release of chemicals from plastics to the environment and to wildlife. Philos. Trans. R. Soc. Lond. B Biol. Sci. 364, 2027-2045. doi: 10.1098/rstb.2008.0284.

van Franeker, J.A., Kühn, S., Anker-Nilssen, T., Edwards, E.W.J., Gallien, F., Guse, N., Kakkonen, J.E., Mallory, M.L., Miles, W., Olsen, K.O., Pedersen, J., Provencher, J., Roos, M., Stienen, E., Turner, D.M., van Loon, W.M.G.M., 2021. New tools to evaluate plastic ingestion by northern fulmars applied to North Sea monitoring data 2002-2018. Mar. Pollut. Bull. 166, 112246. doi: 10.1016/j.marpolbul.2021.112246.

Vlietstra, L.S., Parga, J.A., 2002. Long-term changes in the type, but not amount, of ingested plastic particles in shorttailed shearwaters in the southeastern Bering Sea. Mar. Pollut. Bull. 44, 945-955. doi: 10.1016/S0025-326X00130-3.

Wania, F., MacKay, D., 1996. Peer reviewed: Tracking the distribution of persistent organic pollutants. Environ. Sci. Technol. 30, 390A-396A. doi: 10.1021/es962399q.

Wilcox, C., Carlile, N., Hardesty, B.D., Reid, T., 2021. Assessing multiple threats to seabird populations using flesh-footed shearwaters Ardenna carneipes on Lord Howe Island, Australia as case study. Sci. Rep. 11, 7196. doi: 10.1038/ s41598-021-86702-4.

Wilcox, C., Mallos, N.J., Leonard, G.H., Rodriguez, A., Hardesty, B.D., 2016. Using expert elicitation to estimate the 
impacts of plastic pollution on marine wildlife. Mar. Policy 65, 107-114. doi: 10.1016/j.marpol.2015.10.014.

Wilcox, C., Van Sebille, E., Hardesty, B.D., 2015. Threat of plastic pollution to seabirds is global, pervasive, and increasing. Proc. Natl. Acad. Sci. U.S.A. 112, 11899-11904. doi: 10.1073/ pnas.1502108112.

Williams, T., 1995. The penguins. Oxford University Press, Oxford, UK.

Wright, S.L., Thompson, R.C., Galloway, T.S., 2013. The physical impacts of microplastics on marine organisms: a review. Environ. Pollut. 178, 483-492. doi: 10.1016/j.envpol.2013.02.031.

Yamashita, R., Takada, H., Murakami, M., Fukuwaka, M.A., Watanuki, Y., 2007. Evaluation of noninvasive approach for monitoring PCB pollution of seabirds using preen gland oil. Environ. Sci. Technol. 41, 4901-4906. doi: 10.1021/es0701863.

Yamashita, R., Takada, H., Nakazawa, A., Takahashi, A., Ito, M., Yamamoto, T., Watanabe, Y.Y., Kokubun, N., Sato, K., Wanless, S., Daunt, F., Hyrenbach, D., Hester, M., Deguchi, T., Nishizawa, B., Shoji, A., Watanuki, Y., 2018. Global monitoring of persistent organic pollutants (POPs) using seabird preen gland oil. Arch. Environ. Contam. Toxicol. 75, 545-556. doi: 10.1007/s00244-018-0557-3.

Yamashita, R., Tanaka, K., Yeo, B.G., Takada, H., van Franeker, J.A., Dalton, M., Dale, E., 2019. Hazardous chemicals in plastics in marine environments: international pellet watch, In: Takada, H., Karapanagioti, H.K. (eds.), Hazardous chemicals associated with plastics in the marine environment, $\mathrm{pp}$. 163-183, Springer International Publishing, Cham. doi: 10.1007/698_2018_299.

Yeo, B.G., Takada, H., Yamashita, R., Okazaki, Y., Uchida, K., Tokai, T., Tanaka, K., Trenholm, N., 2020. PCBs and PBDEs in microplastic particles and zooplankton in open water in the Pacific Ocean and around the coast of Japan. Mar. Pollut. Bull. 151, 110806. doi: 10.1016/j.marpolbul.2019.110806.

Zheng, G., Wan, Y., Shi, S., Zhao, H., Gao, S., Zhang, S., An, L., Zhang, Z., 2018. Trophodynamics of emerging brominated flame retardants in the aquatic food web of Lake Taihu: relationship with organism metabolism across trophic levels. Environ. Sci. Technol. 52, 4632-4640. doi: 10.1021/acs. est.7b06588. 